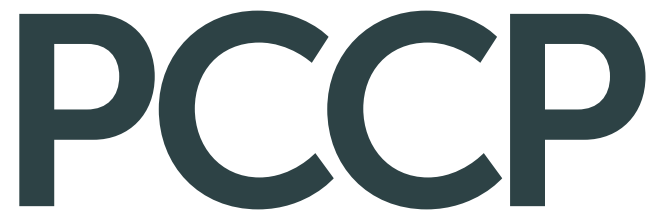

Physical Chemistry Chemical Physics www.rsc.org/pccp
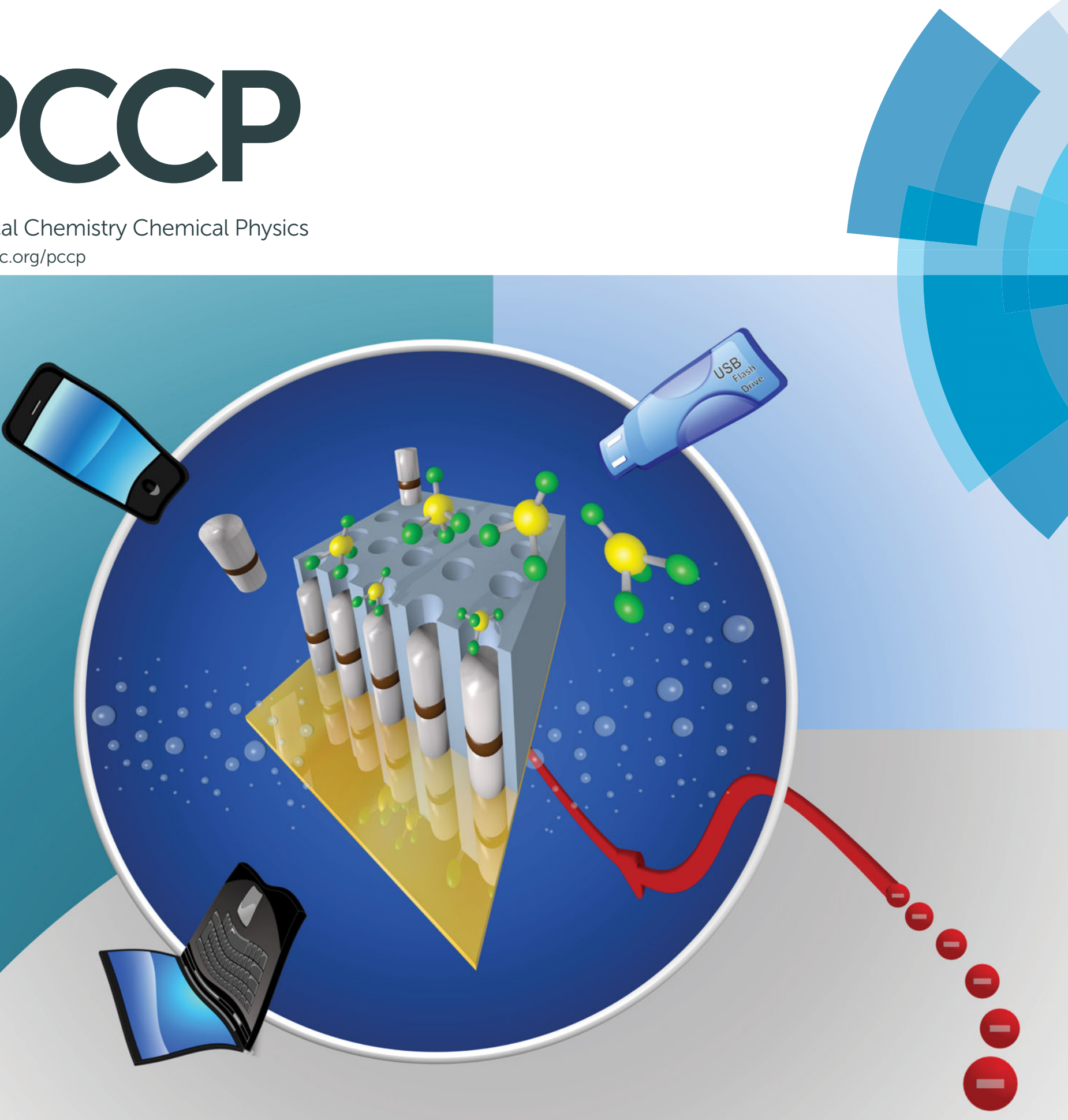

ISSN 1463-9076

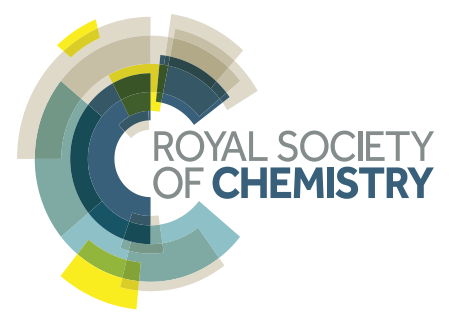




\section{Electrodeposition from supercritical fluids}

Cite this: Phys. Chem. Chem. Phys., 2014, 16, 9202

Received 23rd November 2013, Accepted 23rd December 2013

DOI: $10.1039 / \mathrm{c3cp} 54955 \mathrm{k}$

www.rsc.org/pccp

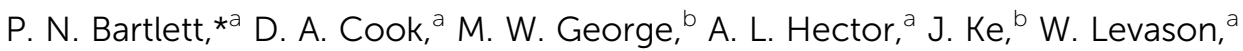 \\ G. Reid, ${ }^{\mathrm{a}}$ D. C. Smith ${ }^{\mathrm{C}}$ and W. Zhang ${ }^{\mathrm{a}}$
}

\section{Introduction}

The field of supercritical fluid electrodeposition continues a long history of development of materials production and deposition methods which underpin nearly all modern technology. The importance and sophistication of materials deposition techniques can be seen in the cost of silicon fabrication facilities used to produce integrated circuits which are measured in billions of dollars. There now exists a wide range of deposition technologies. Vacuum techniques such as thermal evaporation, sputtering, chemical vapour deposition and molecular beam epitaxy are particularly suited to the deposition of high quality thin films. Such techniques have enabled the engineering of the fundamental quantum mechanical states of electrons in semiconductor structures leading to quantum well lasers in DVD players, quantum cascade lasers for chemical sensing, and entirely new fundamental physics, e.g. the fractional quantum Hall effect. Spin-coating and printing are two deposition techniques which have been used for a very long time, but which have been exploited in new ways recently. Much of this renewed interest has come about because of the discovery and application of organic semiconductors for applications such as flexible electronics. Whilst materials deposition is ubiquitous in technology, specific techniques can be found in particular applications in which their unique characteristics can out perform other techniques. For instance, as supercritical fluids have no surface tension and improved mass transport over liquids they have advantages for thermal deposition into high aspect ratio trenches and pores. ${ }^{1}$ Supercritical fluids are also particularly good at swelling polymers in a controllable manner to allow the deposition of nanoparticles into existing polymers structures. ${ }^{2}$

\footnotetext{
${ }^{a}$ Chemistry, The University of Southampton, Southampton SO17 1BJ, UK. E-mail: P.N.Bartlett@soton.ac.uk

${ }^{b}$ School of Chemistry, The University of Nottingham, Nottingham NG7 2RD, UK

${ }^{c}$ Physics \& Astronomy, The University of Southampton, Southampton SO17 1BJ, UK
}

In this perspective we will focus on electrodeposition from supercritical fluids and in particular on the underlying physical chemistry of this new field. Since its introduction in the early 1800 s, electrodeposition has become widely exploited because it has a combination of capabilities not found together in other deposition techniques. ${ }^{3,4}$ These include: conformal deposition onto and into large complex objects; spatially defined growth allowing deposition onto complex structures only where required and allowing contiguous axial deposition through pores without blocking; direct control over the driving force for deposition through the applied potential; in operando measurement of electrical properties of the deposit during growth allowing active feedback; highly efficient use of reagents.

This perspective focuses on a relatively new development in the field of electrodeposition, supercritical fluid electrodeposition (SCFED). Supercritical fluids have a number of key advantages for electrodeposition. These include (i) a lack of surface tension which enables electrodeposition onto fragile substrates, (ii) good pore penetration and mass transport allowing deposition into high aspect ratio nanopores ${ }^{1}$ and small diameter $(<4 \mathrm{~nm})$ nanopores, ${ }^{5}$ (iii) a range of relatively easily accessible supercritical fluids with high chemical stability and thus large deposition windows, which allow the deposition of reactive materials such as germanium, ${ }^{6}$ and (iv) the possibility to increase the deposition temperature with a specific fluid to above the critical temperature. Whilst the technique is still in its infancy, it is possible to envisage technological areas in which SCFED may find unique applications. A likely example is in the production of few nanometre diameter nanowires and nanowire based devices, e.g. Fig. 1.

There are many, varied reasons for the interest in nanowires for applications. These include at the simplest level the possibility of further miniaturisation of existing electronic ${ }^{7}$ and data storage ${ }^{8}$ components. The proximity of the surface to the whole of the bulk of the nanowire makes nanowire chemical and biochemical sensors capable of single molecule sensitivity. ${ }^{9}$ In the field of thermoelectric 


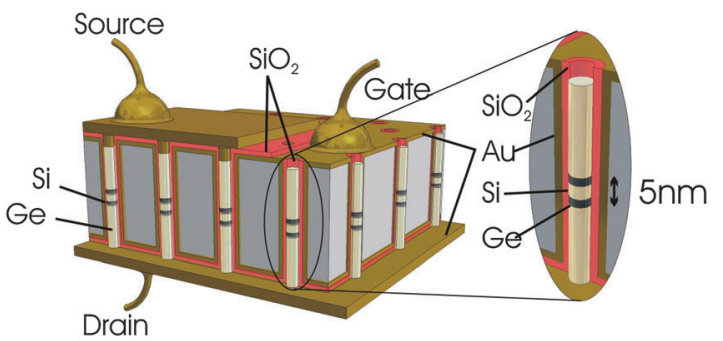

Fig. 1 Concept of a device which supercritical fluid electrodeposition may enable in the future. The concept consists of a multiple resonant tunnel diode memory with element separation of $5 \mathrm{~nm}$. Electrodeposition is particularly suited to the production of axial heterostructures like the $\mathrm{Si} / \mathrm{Ge}$ quantum dot structure shown here. Using a supercritical fluid as the solvent would have advantages for pore penetration, deposition of reactive materials and high temperature deposition for materials quality.

materials nanowires show increased figure of merit over bulk materials because of decreased phononic thermal conductivity. ${ }^{10}$ Other routes by which nanowires could contribute to energy efficiency and generation include photovoltaic nanowire devices ${ }^{11}$ and piezoelectric nanowires. ${ }^{12}$ The fact that nanowires are less susceptible to defects means that it may be possible to produce ultra-strength materials from them. ${ }^{13}$ Most of the near to market applications use nanowires with diameters in excess of $10 \mathrm{~nm}$, however initial investigations of ultrathin nanowires ${ }^{14}$ suggest that these may be even more exciting in the medium term.

Supercritical fluids may bring a number of advantages for electrodeposition and for the electrodeposition of nanowires and nanostructures. However, there are significant challenges associated with trying to utilise SCFs for electrochemistry and electrodeposition. These include dissolution of a sufficient concentration of ionic species to produce a suitably conductive fluid, identifying sufficiently soluble and stable electrochemical precursors to produce useful deposition rates, ensuring the formation of a homogeneous solution and the development of safe and practical high pressure apparatus. Below we discuss these issues.

\section{Properties of SCFs and measurement of solubility and conductivity}

A supercritical fluid is defined as a substance above its critical temperature $\left(T_{\mathrm{c}}\right)$ and critical pressure $\left(p_{\mathrm{c}}\right)$, and as such they are unique solvents that combine the properties of liquids and gases, Table 1. SCFs have recently been exploited as green alternatives to conventional organic solvents in a variety of applications including: (i) separation processes such as extraction, sorption processes, chromatography, and drying; (ii) mechanical processes such as extrusion, homogenisation, emulsification, micronisation, crystallisation, impregnation and encapsulation, and (iii) chemical and biochemical reactions. ${ }^{15-21}$ Many processes utilising sub- and supercritical fluids have been investigated for a wide range of industries including agriculture and food, cosmetics, pharmaceuticals, medicine, coatings, textiles, electronics and semiconductors, and waste treatment. ${ }^{22-27}$ The properties of SCFs have received considerable attention, and have been extensively reviewed. ${ }^{28-33}$

Unlike conventional solvents, the physical properties of SCFs can be easily tuned by changing either temperature or pressure, or both. This advantage has been widely exploited in supercritical fluid extraction for separating products and in supercritical fluid reactions for achieving high yield and selectivity. ${ }^{28-33}$ The tuneable properties of SCFs also have applications in processing nano-materials, e.g. supercritical drying of highly porous $\beta$-chitin structures, ${ }^{35}$ and preparation of free-standing arrays of CdS nanowires. ${ }^{36}$

In order to successfully electrodeposit from a supercritical fluid we must consider their phase behaviour. SCFs are often illustrated with a $p-T$ phase diagram of a single-component system. One such diagram is presented in Fig. 2 using trifluoromethane $\left(\mathrm{CHF}_{3}\right)$ as an example, for which $T_{\mathrm{c}}$ and $p_{\mathrm{c}}$ are $299.1 \mathrm{~K}$ and $4.82 \mathrm{MPa}$, respectively. The supercritical state is represented by the shaded area in Fig. 2. Density is one of the most important physical properties of SCFs; density can be shown as isochores in the $p-T$ phase diagram, e.g. 7 isochores of $\mathrm{CHF}_{3}$ are depicted in Fig. 2, with the density between 0.25 and $1.45 \mathrm{~g} \mathrm{~cm}^{-3}$. It is worth pointing out that only a certain combination of temperature and pressure within the shaded area can provide the desired properties for use of SCFs as solvents. For example, consider $\mathrm{CHF}_{3}$ under the conditions of $400 \mathrm{~K}$ and $15 \mathrm{MPa}$, which is $\sim 100 \mathrm{~K}$ above its $T_{\mathrm{c}}$, and $\sim 10 \mathrm{MPa}$ above its $p_{\mathrm{c}}$. At $400 \mathrm{~K}$ and $15 \mathrm{MPa} \mathrm{CHF}_{3}$ is in the supercritical state; however its density is only $6.4 \mathrm{~mol} \mathrm{dm}^{-3}$ and compared with liquid $\mathrm{H}_{2} \mathrm{O}$, having a density of $55.6 \mathrm{~mol} \mathrm{dm}^{-3}$ at $298 \mathrm{~K}$, or liquid $\mathrm{CHF}_{3}$, having a density of $20 \mathrm{~mol} \mathrm{dm}^{-3}$ at its boiling point, the density of $\mathrm{CHF}_{3}$ at $400 \mathrm{~K}$ and $15 \mathrm{MPa}$ is too low for it to be a good solvent for ionic species, and therefore too low for it to be a good solvent for electrodeposition.

The dissolution of ionic species in SCFs is one of the key challenges to carry out supercritical fluid electrodeposition because most of the SCFs with easily accessible critical temperatures are non-polar or low polarity molecules and therefore are

Table 1 Density, viscosity, and diffusion coefficient of SCFs, gases and liquids ${ }^{28,34}$

\begin{tabular}{llll}
\hline State & Gas & Supercritical fluid & Liquid \\
\hline Temperature/K & 298 & $T_{\mathrm{c}}$ & 298 \\
Pressure/MPa & 0.1 & $p_{\mathrm{c}}$ & 0.1 \\
Density/g cm & & $0.2-0.5$ & $0.6-2$ \\
Diffusion coefficient $/ \mathrm{cm}^{2} \mathrm{~s}^{-1}$ & $0.6-2 \times 10^{-3}$ & $0.5-4 \times 10^{-3}$ & $0.2-2 \times 10^{-5}$ \\
Viscosity/MPa s & $0.1-0.4$ & $0.01-0.03$ & $0.2-20$
\end{tabular}




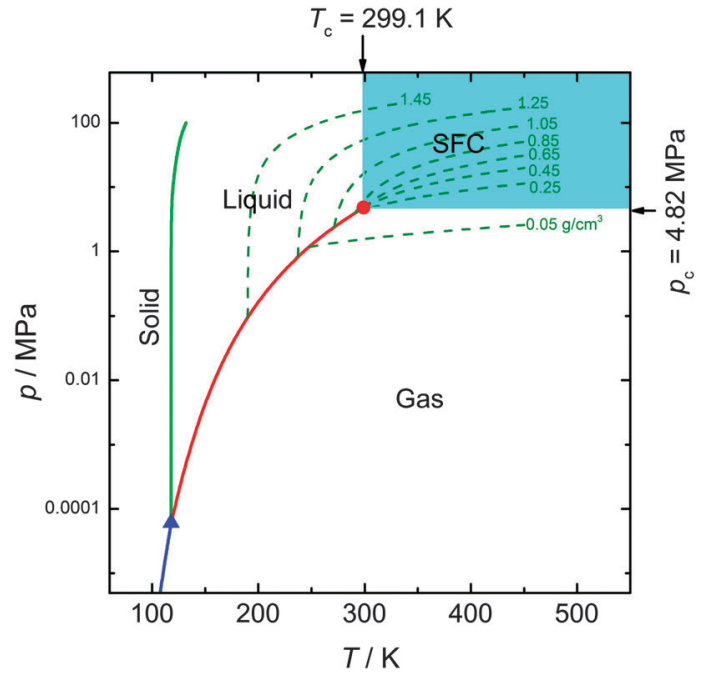

Fig. 2 Phase diagram of pure $\mathrm{CHF}_{3}$. $\bullet$, the critical point of $\mathrm{CHF}_{3} ; \mathbf{\Lambda}$, the triple point of $\mathrm{CHF}_{3}$; SCF, supercritical fluid, shaded in cyan. The red, green and blue curves are the gas-liquid, liquid-solid, and gas-solid phase boundary, respectively. The dashed curves represent the isochores corresponding to the density between 0.05 and $1.45 \mathrm{~g} \mathrm{~cm}^{-3}$. The critical temperature $\left(T_{c}\right)$ and critical pressure $\left(p_{c}\right)$ are $299.1 \mathrm{~K}$ and $4.82 \mathrm{MPa}$, respectively, indicated by the arrows in the figure.

not good media for ion solvation. Electrostatic interactions contribute more than $80 \%$ of the total ion-solvent interactions. ${ }^{37}$ Based on the Born equation, the electrostatic solvation energy $\left(\Delta G_{\mathrm{ES}}\right)$, defined as the difference between the electrostatic free energy of an ion in vacuo and that in a solution, can be calculated from the ionic charge, ionic radius, and dielectric constant $\left(\varepsilon_{\mathrm{r}}\right)$. Fig. 3a shows the calculated $\Delta G_{\mathrm{ES}}$ for a univalent ion with a radius of $0.2 \mathrm{~nm}$ in a medium with a dielectric constant ranging from 1 to 40 . It can be seen that $\Delta G_{\mathrm{ES}}$ decreases very rapidly with the increase of $\varepsilon_{\mathrm{r}}$ in the low dielectric constant region $\left(\varepsilon_{\mathrm{r}}<7\right)$, but decreases rather slowly in the high dielectric constant region $\left(\varepsilon_{\mathrm{r}}>20\right)$. In order for the electrolyte to dissolve and dissociate in the solution $\varepsilon_{\mathrm{r}}$ needs to be large enough so that the Gibbs free energy for solvation, $\Delta G_{\mathrm{ES}}$, is sufficiently negative to overcome the lattice energy. On the other hand, for those solvents with dielectric constant greater than 20 , the difference in $\Delta G_{\mathrm{ES}}$ is rather small so that the effect of dielectric constant on the solubility is not significant when only the electrostatic solvation energy is taken into account. The $\varepsilon_{\mathrm{r}}$ region between 7 and 20 is highlighted in Fig. 3. This is why most non-aqueous electrochemistry is carried out in solvents with a dielectric constant above 10 such as acetonitrile $\left(\varepsilon_{\mathrm{r}}=36.6\right), N, N^{\prime}$-dimethylformamide $\left(\varepsilon_{\mathrm{r}}=38.3\right)$, dimethylsulfoxide $\left(\varepsilon_{\mathrm{r}}=47.2\right)$ or propylene carbonate $\left(\varepsilon_{\mathrm{r}}=66.1\right)$.

Fig. $3 \mathrm{~b}$ plots the dielectric constant of three fluorinated hydrocarbons (HFCs) as a function of pressure at temperatures above their corresponding $T_{\mathrm{c}}$. It is clear that the dielectric constant increases with increasing pressure for all three HFCs, suggesting that the solubility of ionic species is higher at high pressures. In addition, the solubility of ionic species can be substantially higher in $\mathrm{CH}_{2} \mathrm{~F}_{2}$ than in the other two HFCs (i.e. $\mathrm{CHF}_{3}$ and $\mathrm{CF}_{3} \mathrm{CH}_{2} \mathrm{~F}$ ) because the dielectric constant of

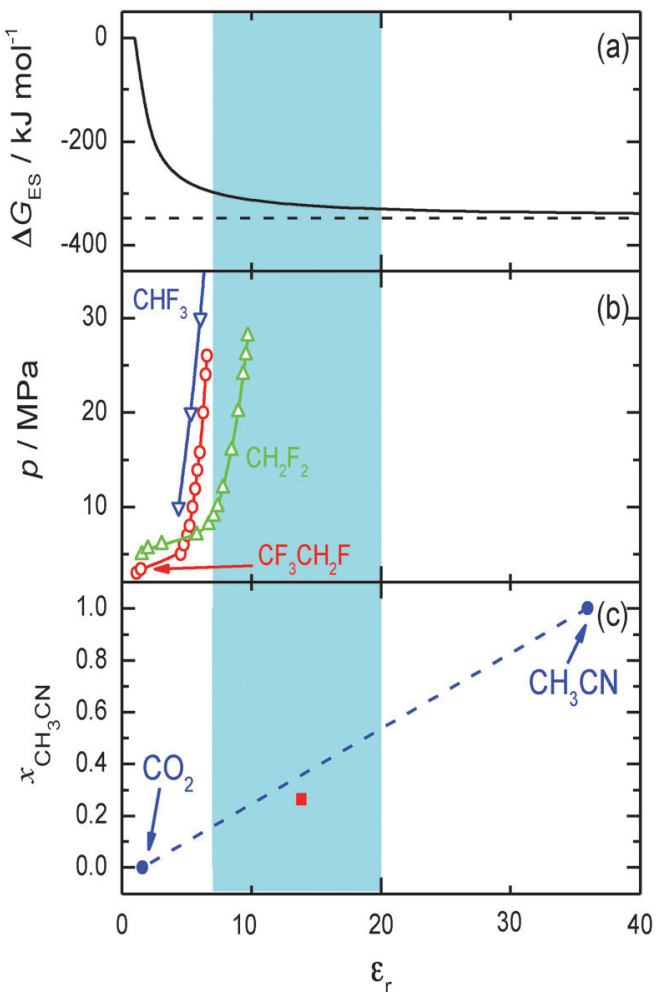

Fig. 3 (a) Plot of the electrostatic solvation energy $\left(\Delta G_{E S}\right)$ of a univalent ion against dielectric constant $\left(\varepsilon_{r}\right)$, calculated by the Born equation with the ionic radius of $0.2 \mathrm{~nm}^{37}$ (b) The effect of pressure $(p)$ on $\varepsilon_{\mathrm{r}}$ for three fluorinated hydrocarbons at $T>T_{\mathrm{c}}$ of each solvent: $\nabla, \mathrm{CHF}_{3}$ at $335 \mathrm{~K}$; $\mathrm{O}$, $\mathrm{CF}_{3} \mathrm{CH}_{2} \mathrm{~F}$ at $383 \mathrm{~K} ; \triangle \mathrm{CH}_{2} \mathrm{~F}_{2}$ at $363 \mathrm{~K}^{38-40}$ (c) $\varepsilon_{\mathrm{r}}$ of the binary system of $\mathrm{CO}_{2}+\mathrm{CH}_{3} \mathrm{CN}$. The dashed line represents the linear interpolation of $\varepsilon_{\mathrm{r}}$ as a function of the mole fraction of $\mathrm{CH}_{3} \mathrm{CN}\left(x \mathrm{CH}_{3} \mathrm{CN}\right){ }^{41,42} \mathbf{\square}, \varepsilon_{\mathrm{r}}$ of a mixture of $\mathrm{CO}_{2}+\mathrm{CH}_{3} \mathrm{CN}$ measured at $25{ }^{\circ} \mathrm{C}$ and $5.0 \mathrm{MPa} .{ }^{43}$ The composition of the mixture is interpolated from the vapour-liquid phase equilibrium data reported by Reighard et al. ${ }^{44}$

$\mathrm{CH}_{2} \mathrm{~F}_{2}$ reaches 7 when the pressure is over $8 \mathrm{MPa}$. Hence, the selection of SCFs with high dielectric constant is the key to increasing the solubility of ionic species.

An alternative method to increase the dielectric constant is the use of mixed solvents, e.g. adding polar co-solvents into non-polar SCFs. This has been a widely accepted concept in all sorts of applications of SCFs. ${ }^{45-49}$ In particular, the enhancement of the solubility of polar substances in $\mathrm{CO}_{2}$ has been extensively studied by using acetone, methanol, ethanol, acetonitrile, etc. as co-solvents. Fig. 3c shows the effect of the mole fraction of $\mathrm{CH}_{3} \mathrm{CN}\left(\varepsilon_{\mathrm{r}}=36\right)$ on the dielectric constant of the binary system of $\mathrm{CO}_{2}+\mathrm{CH}_{3} \mathrm{CN}$. One can see that it is crucial to add $10-18 \%$ (mole fraction) of $\mathrm{CH}_{3} \mathrm{CN}$ into $\mathrm{CO}_{2}$ to achieve a dielectric constant of 7. A much higher concentration of $\mathrm{CH}_{3} \mathrm{CN}\left(\right.$ e.g. $\left.x_{\mathrm{CH}_{3} \mathrm{CN}}>0.5\right)$ may not be necessary because it will not significantly decrease $\Delta G_{\mathrm{ES}}$, but makes the solution more 'liquid-like', and hence slows down the mass transport.

High-pressure electrochemistry cells are the key equipment for electrodeposition in SCFs. The general design considerations include maximum operating temperature and pressure, electrode insulation and installation, material comparability, 

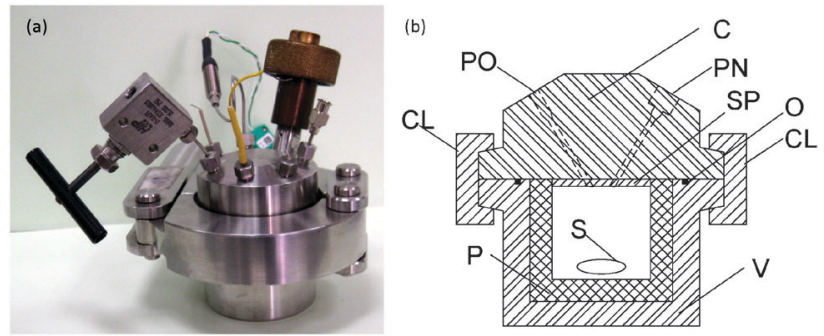

Fig. 4 High-pressure electrochemistry cell: (a) the electrochemistry cell with the electrodes installed; (b) schematic diagram, C, cap; CL, clamp; O; O-ring; P, PEEK pot; PO; SSI type port; PN; port for the needle valve; $S$, magnetic stirrer; SP, PTFE spacer; $V$, stainless steel vessel. More details can be found from ref. 6 and 34 .

and high-pressure safety. (Safety note: the illustrations shown here are purely schematic and should not be regarded as engineering drawings for the construction of safe high-pressure cells. Anyone wishing to build such equipment for themselves must carry out their own safety evaluation.) There are also a number of more subjective requirements, such as stirring the fluid in the cell, dismantling and reassembling the cell frequently and quickly, and convenience of transferring reagents. One cell design is given in Fig. 4. Briefly, the cell consists of a $10 \mathrm{~cm}^{3}$ cylindrical vessel and a cap at its top, constructed from stainless steel. The cap has a fitted needle valve and 6 ports for SSI (Scientific Systems Inc.) type electrodes, thermocouples and fluid inlet/outlet. The vessel and the cap are assembled using a failsafe clamp system, incorporating a disposable elastomeric O-ring. ${ }^{50}$ Recently, a pot made from PEEK (polyether ether ketone) was added to the vessel, together with a PTFE spacer fixed on the cap to reduce contamination from the stainless-steel inner surface. ${ }^{6}$

Electrodeposition requires working solutions with low ohmic resistance and high concentrations of supporting electrolytes and reagents. Since such data on working solutions are not readily available in the literature for supercritical fluid systems, it is essential to acquire a fundamental understanding on the electrical conductivity and phase behaviour of working solutions at high temperature and high pressure. For this purpose, specialised high pressure equipment has been utilised for studying the conductivity and phase behaviour of multi-component systems; two examples of such equipment are shown in Fig. 5. The detailed description of the equipment can be found from the respective publications. ${ }^{34,51,52}$

\section{Electrochemistry in supercritical fluids}

It is appropriate to begin this section with a quotation from Darr and Poliakoff which is useful to keep in the forefront of one's mind “Working with supercritical fluids involves high pressures and sometimes high temperatures. Nearly always, it will always be easier to carry out an experiment under conventional conditions than supercritically". 53 This, in our experience, is definitely true in the case of electrochemistry where, when working at elevated temperatures and pressures it is no longer a trivial matter to polish the electrode between measurements,
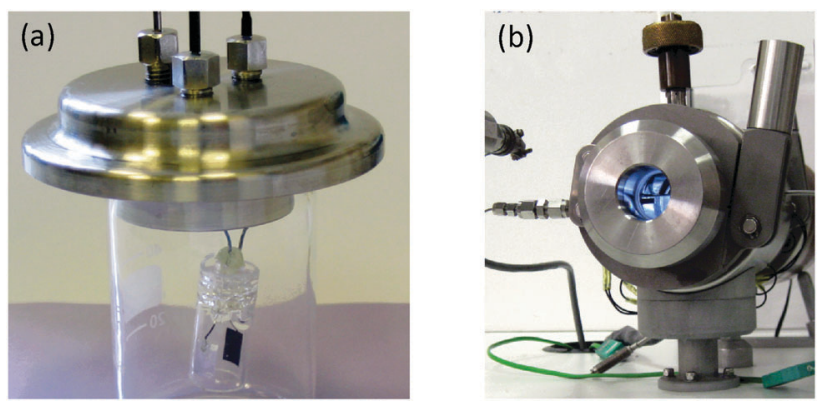

Fig. 5 (a) Conductivity cell with two platinum electrodes. The electrode is soldered to a platinum wire, which is insulated with PEEK tubing and sealed into a stainless steel holder for installing in a high-pressure autoclave. (b) Variable-volume view cell for studying the phase behaviour of multicomponent systems. The fluid mixture with a given concentration of supporting electrolyte and reagents is introduced into the cell and sealed. The conditions (temperature and pressure) corresponding to a homogeneous, single-phase state can be determined visually by changing the volume of the cell at a given temperature.

to find well-behaved reference electrodes or to take for granted the function of the counter electrode. On the other hand supercritical fluids have unique properties and sometimes the additional complexity allows results which cannot be achieved another way.

The earliest studies in supercritical fluids other than water appear to have been by Williams and Naiditch who reported the electrodeposition of $\mathrm{Ag}$ from "dense gaseous solutions" of $\mathrm{AgNO}_{3}$ in ammonia. ${ }^{54}$ These experiments were carried out in sealed glass vessels using two Pt electrodes. Dendritic growth of $\mathrm{Ag}$ was observed on the cathode. The deposition was carried out slightly (7 K) above the critical temperature for $\mathrm{NH}_{3}$ so it is not certain that the fluid was in the supercritical state.

Subsequently in 1981 Silvestri et al. reported results for a preliminary study of supercritical $\mathrm{CO}_{2}$, bromotrifluoromethane, hydrogen chloride and ammonia as solvents for electrochemistry. ${ }^{55}$ Their focus was on the possibility of using these supercritical fluids as solvent for electrosynthesis. They report that "a solution of tetrabutylammonium iodide in $\mathrm{CO}_{2}$ was a poor conductor in the liquid, as well as in the supercritical state. Bromotrifluoromethane, in which the electrolyte was practically insoluble, also proved to be a very poor conductor". They had greater success with the more polar, and therefore higher dielectric, solvents $\mathrm{scHCl}$ and $\mathrm{scNH}_{3}$ and they report long-term electrolyses (4000 $\mathrm{C}$ charge passed) for $\mathrm{Ag}$ and Fe electrodes in $\mathrm{scNH}_{3}$. $\mathrm{scHCl}$ was found to be difficult to work with because it is highly corrosive. Nevertheless they were able to produce elemental iodine by electrolysis of $\mathrm{KI}$ in $\mathrm{scHCl}$.

Between 1984 and 1997 Bard's group published a series of studies of electrochemistry in supercritical fluids, $\mathrm{NH}_{3}{ }^{56-58}$ water, ${ }^{59-62}$ acetonitrile ${ }^{63,64}$ and $\mathrm{SO}_{2} \cdot{ }^{65}$ In these studies they developed the techniques for working with supercritical fluids, and particularly corrosive supercritical fluids such as water, and studied the electrochemistry of both inorganic and organic redox systems, including $\mathrm{Cu}$ deposition, ${ }^{62}$ halide oxidation, ${ }^{60}$ oxygen reduction, ${ }^{60}$ and hydroquinone oxidation ${ }^{60}$ all from $\mathrm{scH}_{2} \mathrm{O}$, and solvated electrons and organic redox couples in $\mathrm{scNH}_{3}{ }^{56-58}$

The systems investigated by Bard's group were all quite polar fluids. These, in general, have the disadvantage of high 
critical temperatures and pressures. Although less polar supercritical fluids such as $\mathrm{scCO}_{2}$ are more benign to work with, they present the electrochemist with a significant problem in that they have very low dielectric constants and it is therefore difficult to achieve sufficient dissolution and dissociation of the electrolyte to achieve reasonable solution conductivity. Thus, for example, Abbott and Harper ${ }^{66}$ briefly studied the electrochemistry of $\left[\mathrm{Ndodecyl}_{4}\right]_{2}\left[\mathrm{Ni}(\mathrm{mnt})_{2}\right]$ (mnt $=$ maleonitrile) in $\mathrm{scCO}_{2}$ using hydrophobic electrolytes (tetradecylammonium tetraphenylborate), they found some conductivity $\left(\sim 10^{-6} \mathrm{~S} \mathrm{~cm}^{-1}\right)$ and obtained some, poorly resolved, voltammetry.

One approach to overcome this problem is to use co-solvents such as methanol or acetonitrile. These mixtures still form single phase supercritical systems, although it is of course essential to characterise the phase behaviour to establish the appropriate conditions in terms of $T$ and $p$, but the presence of the co-solvents increases the solubility of ionic species and dissociation of the electrolyte, and hence the conductivity of the fluid. To increase the conductivity of $\operatorname{scCO}_{2}\left(\varepsilon_{\mathrm{r}}=1.5\right.$ at $308 \mathrm{~K}$ and $\left.10 \mathrm{MPa}^{41}\right), \mathrm{CH}_{3} \mathrm{OH}$ and $\mathrm{CH}_{3} \mathrm{CN}$ have been previously explored as co-solvents. ${ }^{67}$ A review of electrochemistry in $\mathrm{scCO}_{2}$ and $\mathrm{scCO}_{2}$ with various co-solvent, covering the literature up to 1998, has been provided by Grinberg and Mazin. ${ }^{68}$

An alternative approach is to use hydrofluorocarbons (HFCs) as supercritical solvents as these are polar and give higher dielectric constant fluids whilst retaining reasonable critical temperatures and pressures. Early work in this area was carried out by Olsen and Tallman ${ }^{69}$ who studied the electrochemistry of ferrocene and the cobalticenium cation at microdisc electrodes in $\mathrm{scCHClF}_{2}$ with millimolar concentrations of $\left[\mathrm{N}^{n} \mathrm{Bu}_{4}\right]\left[\mathrm{BF}_{4}\right]$ electrolyte. In addition they also investigated the use of $\mathrm{scCHF}_{3}$ and found good voltammetry for ferrocene and the cobalticenium cation with microdisc electrodes (Fig. 6). Subsequently, in a series of papers, Goldfarb and Corti $^{70-72}$ studied electrochemistry of decamethylferrocene in scCHF 3 containing $\left[\mathrm{N}^{n} \mathrm{Bu}_{4}\right]\left[\mathrm{PF}_{6}\right]$ electrolyte.

At around the same time Abbott's group also published a series of papers on electrochemistry in supercritical hydrofluorocarbons. Thus they investigated the use of supercritical 1,1,1,2tetrafluoroethane $\left(\mathrm{CF}_{3} \mathrm{CH}_{2} \mathrm{~F}\right)$ and $\mathrm{scCH}_{2} \mathrm{~F}_{2}$ and demonstrated a wide potential window for these solvents with $\left[\mathrm{N}^{n} \mathrm{Bu}_{4}\right]\left[\mathrm{BF}_{4}\right]$ or $\left[\mathrm{N}^{n} \mathrm{Bu}_{4}\right]\left[\mathrm{ClO}_{4}\right]$ electrolytes allowing oxidation of $\left[\mathrm{Cs}(18 \text {-crown-6) }]^{+}\right.$ and $\mathrm{Xe}$ in liquid $\mathrm{CF}_{3} \mathrm{CH}_{2} \mathrm{~F}^{73}$ They also used supercritical 1,1,1,2tetrafluoroethane with $\left[\mathrm{N}^{n} \mathrm{Bu}_{4}\right]\left[\mathrm{BF}_{4}\right]$ electrolyte as a solvent for the electrochemical reduction of $\mathrm{CO}_{2}$ at $\mathrm{Pt}$ and $\mathrm{Pb}$ electrodes. ${ }^{74}$

In addition to these studies of electrode reactions there have been a limited number of studies of more fundamental issues such as diffusion, effects of solvation and the structure of the double layer. For example Goldfarb and Corti ${ }^{72}$ have published an in depth study of the diffusion coefficient for decamethylferrocene in $\mathrm{scCHF}_{3}$ with $\left[\mathrm{N}^{n} \mathrm{Bu}_{4}\right]\left[\mathrm{PF}_{6}\right]$ electrolyte as a function of the temperature and pressure, taking account of the effects of ion pairing and correlating the results on the basis of the Stokes-Einstein model. Abbott et al. ${ }^{75}$ investigated the effects of solute on the viscosity of $\mathrm{ScCH}_{2} \mathrm{~F}_{2}$ using quartz crystal microbalance measurements and showed that the viscosity could be surprisingly high (8-32 fold increase) at pressures

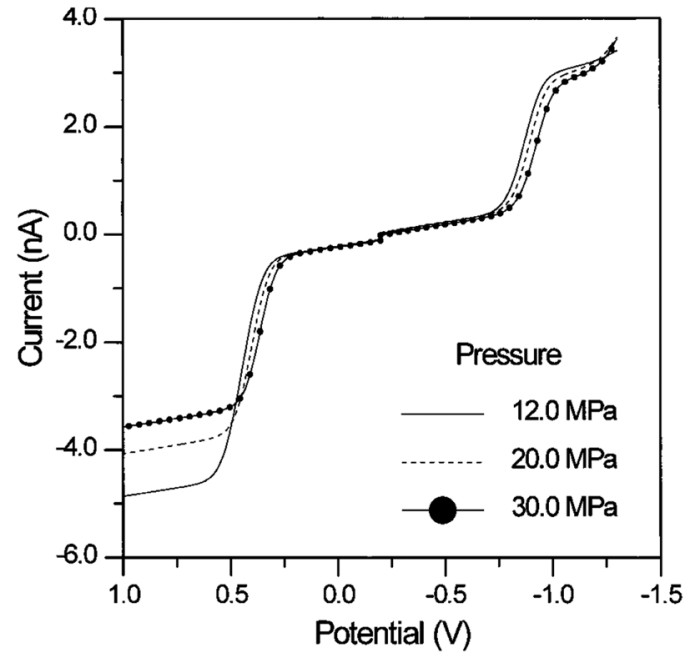

Fig. 6 Comparison of voltammetry of ferrocene and the cobalticenium cation as a function of pressure in supercritical chlorodifluoromethane. Conditions: $90 \mu \mathrm{M}$ Fc, $90 \mu \mathrm{M} \mathrm{Cc}+10.0 \mathrm{mM}^{+}\left[\mathrm{N}^{n} \mathrm{Bu}_{4}\right]\left[\mathrm{BF}_{4}\right] ; 388 \mathrm{~K} ; 25 \mu \mathrm{m}$ diameter Pt disk electrode; scan rate, $20 \mathrm{mV} \mathrm{s}^{-1}$. For clarity, only the forward sweep of each voltammogram is displayed, with the ferrocene wave recorded first and the cobalticenium cation wave immediately after, each wave originating from $-0.20 \mathrm{~V}$. Reprinted with permission from S. A. Olsen and D. E. Tallman, Anal. Chem., 1996, 68, 2054-2061. Copyright 1996 American Chemical Society.

close to the critical value. They also investigated the effects of ion-pairing on the redox potential of ferrocene carboxylic acid in $\mathrm{scCH}_{2} \mathrm{~F}_{2} \cdot{ }^{76}$ Abbott's group are also the only ones to investigate the structure of the double layer in supercritical fluid electrolytes; $\mathrm{scCH}_{2} \mathrm{~F}_{2}$ containing $\left[\mathrm{NR}_{4}\right]\left[\mathrm{BF}_{4}\right]^{77}$ and $\mathrm{scCO}_{2}$ containing long chain quaternary ammonium electrolytes. ${ }^{78}$

\section{New electrolytes}

One of the enduring challenges of electrochemistry in supercritical fluids is the choice of electrolyte in order to achieve high solution conductivity and thus reduce $i R$ drop due to the uncompensated solution resistance. This is particularly important for applications in electrosynthesis or electrodeposition where it is necessary to pass larger currents. A number of studies have been reported in the literature on the conductivity of supercritical fluid electrolytes.

Olsen and Tallman ${ }^{79}$ reported values for the equivalent conductivity for $\left[\mathrm{N}^{n} \mathrm{Bu}_{4}\right]\left[\mathrm{BF}_{4}\right]$ in $\mathrm{scCHClF}_{2}$ at $388 \mathrm{~K}$ between 10 and $24 \mathrm{MPa}$ for concentrations between 6 and $13 \mathrm{mM}$, Fig. 7. They found a non-linear increase in equivalent conductivity with the square root of electrolyte concentration; behaviour indicative of the formation of triple ions $(+)(-)(+)$ or $(-)(+)(-)$ as predicted by the Fuoss-Kraus equation. ${ }^{80}$ Abbott and Eardley ${ }^{81}$ investigated the conductivity of $\left[\mathrm{N}^{n} \mathrm{Bu}_{4}\right]\left[\mathrm{BF}_{4}\right]$ in $\mathrm{ScCH}_{2} \mathrm{~F}_{2}$ and found similar behaviour with evidence for a contribution from triple ions and Goldfarb and Corti, ${ }^{71}$ in an extensive study, found similar effects for $\left[\mathrm{N}^{n} \mathrm{Bu}_{4}\right]\left[\mathrm{ClO}_{4}\right]$ in $\mathrm{scCHF}_{3}$. Jun and Fedkiw reported conductivities in the range $10^{-5}$ to $10^{-4} \mathrm{~S} \mathrm{~cm}^{-1}$ for alkali-metal salts of trifluoroacetates in $\mathrm{scCO}_{2}-\mathrm{CH}_{3} \mathrm{OH}$, with 


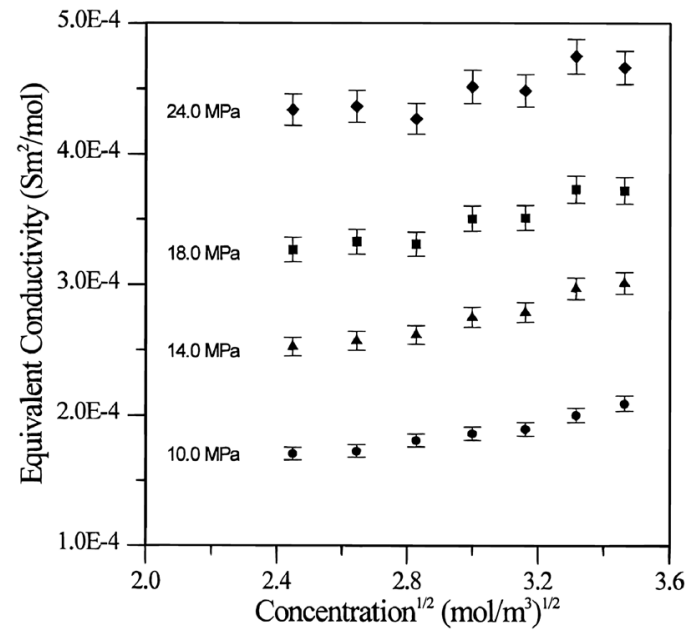

Fig. 7 Equivalent conductivity of supercritical $\mathrm{CHClF}_{2}$ at $388 \mathrm{~K}$ as a function of the square root of $\left[\mathrm{N}^{n} \mathrm{Bu}_{4}\right]\left[\mathrm{BF}_{4}\right]$ concentration. The points (error bars) are the averages (standard deviations) of 5-6 measurements. Data at four densities are shown corresponding to fluid pressures of $10.0(-14.0(\mathbf{\Lambda}), 18.0(\mathbf{\square})$, and $24.0 \mathrm{MPa}(\bullet)$. Reprinted with permission from S. A. Olsen and D. E. Tallman, Anal. Chem., 1996, 68, 2054-2061. Copyright 1996 American Chemical Society.

the highest values in the single phase region obtained for the lithium salt. ${ }^{82}$ In all cases these commercially available electrolytes give solutions with reasonable conductivity but, for electrosynthesis and electrodeposition applications, it would be desirable to find electrolytes with higher conductivity.

The successful development of electrodeposition from supercritical fluids requires careful choice of both electrolytes and reagents. The electrolytes must (i) have good solubility in the SCF, (ii) be dissociated into the constituent ions in the solution, (iii) have a wide electrochemical window (i.e. redox inactive in the potential range to be used), and (iv) be chemically inert with respect to the reagents added. The low polarity of the SCFs used in this work makes (i) and (ii) in particular, key issues to be addressed. Weakly coordinating anions have long been used in coordination and organometallic chemistry with aims including stabilisation of reactive cations, allowing the coordination of weakly bound ligands to metal centres, and enhancing catalysis rates and activities. Typical examples include $\left[\mathrm{BF}_{4}\right]^{-},\left[\mathrm{ClO}_{4}\right]^{-},\left[\mathrm{PF}_{6}\right]^{-},\left[\mathrm{SO}_{3} \mathrm{~F}\right]^{-},\left[\mathrm{BPh}_{4}\right]^{-}$usually in association with alkali metal or large tetra-alkylammonium cations. ${ }^{83}$ The search for even more weakly coordinating anions has resulted in development of the chemistries of fluorinated analogues of $\left[\mathrm{BPh}_{4}\right]^{-},\left[\mathrm{M}\left\{\mathrm{OTeF}_{5}\right\}_{n}\right]^{-}(\mathrm{M}=\mathrm{B}$, As etc. $),\left[\mathrm{Al}\left\{\mathrm{OC}_{(}\left(\mathrm{CF}_{3}\right)_{3}\right\}_{4}\right]^{-}$, and various carboranes. ${ }^{84}$ It is important to remember that weakly coordinating anions are not necessarily chemically inert, many examples of fluoride abstraction from $\left[\mathrm{BF}_{4}\right]^{-}$or $\left[\mathrm{PF}_{6}\right]^{-}$, and B-C bond cleavage in $\left[\mathrm{BPh}_{4}\right]^{-}$are known. ${ }^{83}$ For SCFED, electrolytes based upon tetraalkylammonium cations and weakly coordinating anions seem to be a promising approach. Conductivity studies of $\mathrm{scCO}_{2}, \mathrm{CH}_{2} \mathrm{~F}_{2}$ and $\mathrm{CHF}_{2} \mathrm{CHF}_{2}$ by Abbott et al. ${ }^{73,81}$ used $\left[\mathrm{N}^{n} \mathrm{Bu}_{4}\right]\left[\mathrm{BF}_{4}\right]$ or $\left[\mathrm{N}^{n} \mathrm{Bu}_{4}\right]\left[\mathrm{ClO}_{4}\right]$ as electrolytes. We have used fluorinated tetra-aryl borates $\left(\left[\mathrm{B}\left(\mathrm{Ar}^{\mathrm{F}}\right)_{4}\right]^{-}\right)$which were initially developed by organometallic chemists to address both the tendency of $\left[\mathrm{BPh}_{4}\right]^{-}$to $\pi$-aryl coordination to metal centres and $\mathrm{B}-\mathrm{C}$ bond fission; they are also much more resistant to fluoride abstraction by electrophilic metals than $\left[\mathrm{BF}_{4}\right]^{-}{ }^{83,84}$

The $\left[\mathrm{B}\left(\mathrm{Ar}^{\mathrm{F}}\right)_{4}\right]^{-}$anions with $\mathrm{Ar}^{\mathrm{F}}=\mathrm{C}_{6} \mathrm{H}_{4} \mathrm{~F}, \mathrm{C}_{6} \mathrm{~F}_{5}, 4-\mathrm{CF}_{3} \mathrm{C}_{6} \mathrm{H}_{4}$ and 3,5- $\left(\mathrm{CF}_{3}\right)_{2} \mathrm{C}_{6} \mathrm{H}_{3}$, (Fig. 8) are readily made as sodium salts by reaction of $\mathrm{Na}\left[\mathrm{BF}_{4}\right]$ with the appropriate Grignard reagent $\operatorname{BrMg}\left(\mathrm{Ar}^{\mathrm{F}}\right),{ }^{85-87}$ and can be converted to $\left[\mathrm{NR}_{4}\right]^{+}$salts by metathesis with $\left[\mathrm{NR}_{4}\right] \mathrm{I}$ in $\mathrm{CH}_{2} \mathrm{Cl}_{2}{ }^{88}$ Various $\left[\mathrm{B}\left(\mathrm{Ar}^{\mathrm{F}}\right)_{4}\right]^{-}$salts are commercially

Fluorinated aryl borate anions
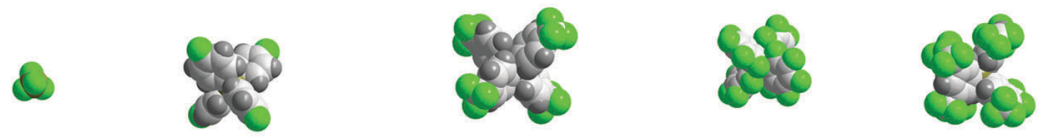

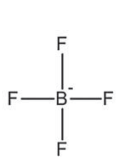

$\left[\mathrm{BF}_{4}\right]-6.6 \mathrm{~A}$

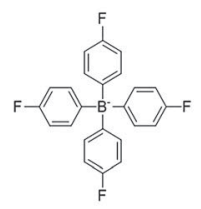

$\left[\mathrm{B}\left(4-\mathrm{C}_{6} \mathrm{H}_{4} \mathrm{~F}\right)_{4}\right]^{-14.5 \AA}$

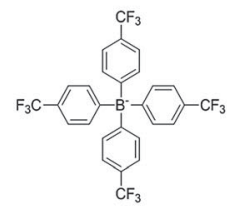

$\left[\mathrm{B}\left(4-\mathrm{C}_{6} \mathrm{H}_{4} \mathrm{CF}_{3}\right)_{4}\right]-16.1 \AA$
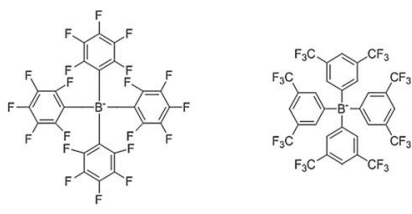

$\left[\mathrm{B}\left(\mathrm{C}_{6} \mathrm{~F}_{5}\right)_{4}\right]-14.5 \AA$

$\left[\mathrm{B}\left\{3,5-\mathrm{C}_{6} \mathrm{H}_{3}\left(\mathrm{CF}_{3}\right)_{2}\right\}_{4}\right]-15.5 \mathrm{~A}$

Tetraalkylammonium cations

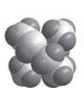

$\left[\mathrm{NEt}_{4}\right]^{+} 8.0 \AA$

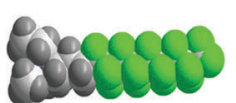

$\left.\left[\mathrm{N}_{\{} \mathrm{CF}_{3}\left(\mathrm{CF}_{2}\right)_{7}\left(\mathrm{CH}_{2}\right)_{3}\right\} \mathrm{Et}_{3}\right]^{+}$

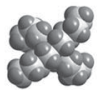

$\left[\mathrm{N}^{n} \mathrm{Bu}_{4}\right]^{+} 12.0 \AA$

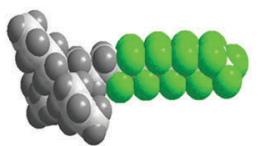

$\left.\left[\mathrm{N}_{\{} \mathrm{CF}_{3}\left(\mathrm{CF}_{2}\right)_{7}\left(\mathrm{CH}_{2}\right)_{3}\right\}^{n} \mathrm{Bu}_{3}\right]^{+}$

Fig. 8 Space filling representations of the cations and anions used as supporting electrolytes (green = F), illustrating their approximate sizes. The dimensions correspond to the estimated diameter across the respective ions based upon van der Waals radii. 
available, although very expensive, but we have found that, depending on the metal reagents used, it is often possible to recover the electrolyte after deposition, re-purify it and hence recycle it.

We also explored the effects of using alkylammonium cations incorporating fluorous "ponytails" to increase solubility. $\left[\mathrm{CF}_{3}\left(\mathrm{CF}_{2}\right)_{7}\left(\mathrm{CH}_{2}\right)_{3} \mathrm{~N}^{n} \mathrm{Bu}_{3}\right] \mathrm{I}$ was made by quaternisation of ${ }^{n} \mathrm{Bu}_{3} \mathrm{~N}$ with $\mathrm{CF}_{3}\left(\mathrm{CF}_{2}\right)_{7}\left(\mathrm{CH}_{2}\right)_{3} \mathrm{I}$, and $\left[\mathrm{CF}_{3}\left(\mathrm{CF}_{2}\right)_{7}\left(\mathrm{CH}_{2}\right)_{3} \mathrm{NMe}_{3}\right] \mathrm{I}$ from $\mathrm{CF}_{3}\left(\mathrm{CF}_{2}\right)_{7}\left(\mathrm{CH}_{2}\right)_{3} \mathrm{NH}_{2}$ and $\mathrm{CH}_{3} \mathrm{I}$, and metathesis with $\mathrm{Na}\left[\mathrm{B}\left(\mathrm{Ar}^{\mathrm{F}}\right)_{4}\right]$ in $\mathrm{CH}_{2} \mathrm{Cl}_{2}$ gave the appropriate $\left[\mathrm{CF}_{3}\left(\mathrm{CF}_{2}\right)_{7}\left(\mathrm{CH}_{2}\right)_{3} \mathrm{NR}_{3}\right]\left[\mathrm{B}\left(\mathrm{Ar}^{\mathrm{F}}\right)_{4}\right]^{88}$ Thermogravimetric analysis studies showed that the cations were thermally stable up to $\sim 180{ }^{\circ} \mathrm{C}$, although subsequent conductivity measurements showed the cations were not significantly better than $\left[\mathrm{N}^{n} \mathrm{Bu}_{4}\right]^{+} .88$

As stressed above, it is important to fully characterise the phase behaviour of the system since addition of significant concentrations $(>10 \mathrm{mM})$ of electrolyte is likely to alter the phase behaviour. This can be done using a view cell of the type described above. These studies should then be complemented by measurements of the conductivity to characterise the behaviour of the different electrolytes. In our work ${ }^{88}$ we started by comparing the behaviour for mixtures of $\mathrm{CO}_{2}$ with $\left[\mathrm{N}^{n} \mathrm{Bu}_{4}\right]\left[\mathrm{BF}_{4}\right]$ and either methanol $\left(\mathrm{CH}_{3} \mathrm{OH}\right)$ or acetonitrile $\left(\mathrm{CH}_{3} \mathrm{CN}\right)$ as the co-solvent. These experiments showed that at similar temperatures and pressures, the solubility of $\left[\mathrm{N}^{n} \mathrm{Bu}_{4}\right]\left[\mathrm{BF}_{4}\right]$ was $\sim 5$ times higher in $\mathrm{CH}_{3} \mathrm{CN}+\mathrm{CO}_{2}$ than in $\mathrm{CH}_{3} \mathrm{OH}+\mathrm{CO}_{2}$.

Fig. 9 shows the phase behaviour of a ternary $\mathrm{CO}_{2}-\left[\mathrm{N}^{n} \mathrm{Bu}_{4}\right]-$ $\left[\mathrm{BF}_{4}\right]-\mathrm{CH}_{3} \mathrm{CN}$ system and illustrates the potential complexity. For the mixture shown in Fig. 9, the three-phase region is a surface with 2 degrees of freedom as required by the phase rule for a ternary system with three phases $(\mathrm{F}=3-3+2=2)$. At high $T$ and $p$ there is a single supercritical phase region which gives way to two and three phase regions as the pressure is decreased. The phase transition is a normal bubble-point transition $\left(\mathrm{L}_{1} \rightarrow \mathrm{L}_{1}+\mathrm{V}\right)$ when the temperature is below $T^{*}$. However, when $T$ is above $T^{*}$, the sequence of the phase transition on decreasing the pressure isothermally is: $\mathrm{L} 1 \rightarrow \mathrm{L} 1+\mathrm{L} 2 \rightarrow \mathrm{L} 1+\mathrm{L} 2+\mathrm{V} \rightarrow \mathrm{L} 1+\mathrm{V}$.

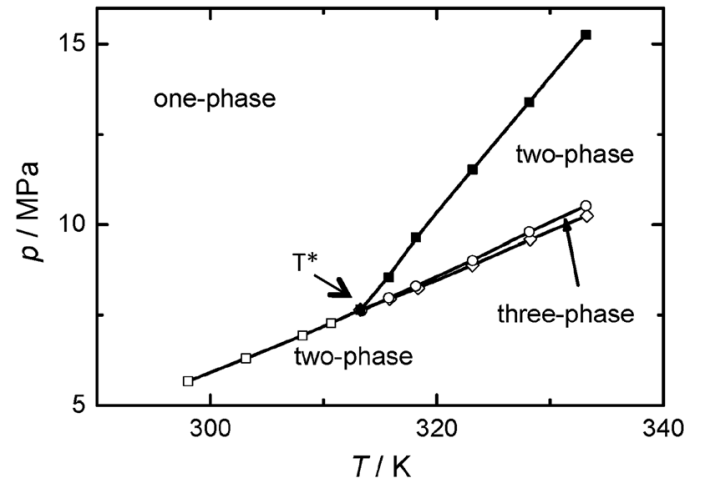

Fig. $9 p-T$ phase diagram of the mixture of $\mathrm{CO}_{2}(1)+\mathrm{CH}_{3} \mathrm{CN}$ (2) + $\left[\mathrm{N}^{n} \mathrm{Bu}_{4}\right]\left[\mathrm{BF}_{4}\right](3)$ with $x_{1}=0.871, x_{2}=0.129$, and $x_{3}=8.3 \times 10^{-4}$. (品) and $(\square)$, the phase boundary between one-, and two-phase region; $(O)$ and $(\diamond)$ mark the region where three phases are in co-existence $\left(\mathrm{L}_{1} \mathrm{~L}_{2} \mathrm{~V}\right)$. The pressure difference between the two three-phase boundaries is less than $0.3 \mathrm{MPa}$ at $333 \mathrm{~K}^{34}$

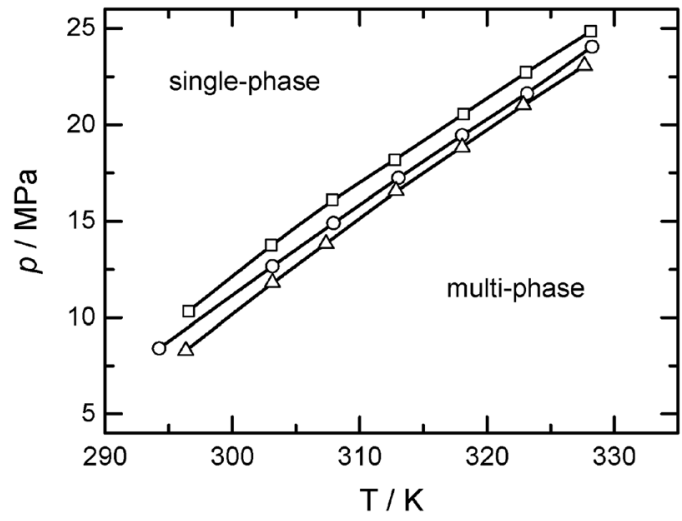

Fig. $10 p-T$ phase diagram of the mixture $\mathrm{CO}_{2}(1)+\mathrm{CH}_{3} \mathrm{CN}$ (2) + $\left[\mathrm{N}^{n} \mathrm{Bu}_{4}\right]\left[\mathrm{BF}_{4}\right](3)$ with and without metal salts (4). $x_{1}=0.89, x_{2}=0.11$ and $x_{3}=1.34 \times 10^{-3}$. (O) no metal salt; $(\triangle)$ with $[\mathrm{Ag}(\mathrm{hfac})(\mathrm{cod})], x_{4}=3.4 \times$ $10^{-4}$, and $(\square)$ with $\left[\mathrm{Cu}(\mathrm{hfac})_{2}\right], x_{4}=3.6 \times 10^{-4.34}$

From these phase behaviour studies for different compositions of the ternary mixture we find that increasing the concentration of $\left[\mathrm{N}^{n} \mathrm{Bu}_{4}\right]\left[\mathrm{BF}_{4}\right]$ increases the pressure required to form a homogeneous solution at a given temperature, and furthermore that the more $\mathrm{CO}_{2}$ there is in the system, the higher the pressure that is required because $\mathrm{CO}_{2}$ is a poor solvent for the ionic species (in this case $\left[\mathrm{N}^{n} \mathrm{Bu}_{4}\right]\left[\mathrm{BF}_{4}\right]$ ). Again this illustrates the potential complexity of the phase behaviour of these systems and why it is essential to experimentally establish the conditions required to form a single supercritical phase.

In principle, the addition of the electrochemical reagents used in the electrodeposition will also alter the phase behaviour. In practice for this system, as shown in Fig. 10, the effects are much smaller, not least because the concentrations of the dissolved reagents are much smaller - the addition of $\sim 3.5 \times$ $10^{-4}$ mole fraction of $[\mathrm{Ag}(\mathrm{hfac})(\mathrm{cod})]$ or $\left[\mathrm{Cu}(\mathrm{hfac})_{2}\right](\mathrm{cod}=$ cycloocta-1,5-diene, hfacH $\left.=\mathrm{CF}_{3} \mathrm{C}(\mathrm{O}) \mathrm{CH}_{2} \mathrm{C}(\mathrm{O}) \mathrm{CF}_{3}\right)$ produces only slight shifts in the supercritical phase boundary $(<2 \mathrm{MPa}$ at fixed temperature).

In order to improve upon the commercial electrolytes we have synthesised a range of anions and cations selected to achieve greater solubility in $\mathrm{scCO}_{2}-\mathrm{CH}_{3} \mathrm{CN}$ by increasing the ion size and by increasing the degree of fluorination. In our conductivity studies we found that the effects of adding a fluorous ponytail (replacing $\left[\mathrm{N}^{n} \mathrm{Bu}_{4}\right]^{+}$by $\left[\mathrm{NR}^{\mathrm{f}} \mathrm{Me}_{3}\right]^{+}$or $\left[\mathrm{NR}^{\mathrm{fn}} \mathrm{Bu}_{4}\right]^{+}$) to the cation were small and did not justify the synthetic effort. This is presumably because the fluorous ponytail does not alter the separation in the ion pair because it is flexible. A similar effect was found by Abbott and Schiffrin ${ }^{89}$ for tetrafluoroborate salts of long chain alkylammonium cations in low dielectric solvents, where the interionic distance in the ion pairs is largely independent of the alkyl chain length due to interpenetration.

Table 2 summarises the data, the structures of the ions and their relative sizes are shown in Fig. 8. In terms of the effect of the anions on the molar conductivity, the general trend is $\left[\mathrm{BF}_{4}\right]^{-} \sim\left[\mathrm{B}\left(4-\mathrm{C}_{6} \mathrm{H}_{4} \mathrm{~F}\right)_{4}\right]^{-}<\left[\mathrm{B}\left(4-\mathrm{C}_{6} \mathrm{H}_{4} \mathrm{CF}_{3}\right)_{4}\right]^{-} \sim\left[\mathrm{B}\left(\mathrm{C}_{6} \mathrm{~F}_{5}\right)_{4}\right]^{-}<$ $\left[\mathrm{B}\left\{3,5-\mathrm{C}_{6} \mathrm{H}_{3}\left(\mathrm{CF}_{3}\right)_{2}\right\}_{4}\right]^{-}$with the highest molar conductivity, 22-26 S cm$~^{2} \mathrm{~mol}^{-1}$, achieved using the $\left[\mathrm{B}\left\{3,5-\mathrm{C}_{6} \mathrm{H}_{3}\left(\mathrm{CF}_{3}\right)_{2}\right\}_{4}\right]^{-}$. 
Table 2 Molar conductivity of the fluorinated supporting electrolytes in a mixed fluid of $\mathrm{CO}_{2}(1)+\mathrm{CH}_{3} \mathrm{CN}$ (2) with a molar ration of $x_{2} / x_{1}=\sim 0.12$ at $328.15 \mathrm{~K}$ and $20 \mathrm{MPa}^{34}$

\begin{tabular}{llrr}
\hline & {$\left[\mathrm{N}^{n} \mathrm{Bu}_{4}\right]^{+}$} & {$\left[\mathrm{NR}^{\mathrm{f}} \mathrm{Me}_{3}\right]^{+}$} & {$\left[\mathrm{NR}^{\mathrm{f} n} \mathrm{Bu}_{3}\right]^{+}$} \\
\hline$\left[\mathrm{BF}_{4}\right]^{-}$ & $2.3^{a, b}(2.4)^{c}$ & - & \multicolumn{1}{c}{} \\
{$\left[\mathrm{B}\left(4-\mathrm{C}_{6} \mathrm{H}_{4} \mathrm{~F}\right)_{4}\right]^{-}$} & - & $3.1(2.2)$ & $3.6(2.4)$ \\
{$\left[\mathrm{B}\left(4-\mathrm{C}_{6} \mathrm{H}_{4} \mathrm{CF}_{3}\right)_{4}\right]^{-}$} & - & $8.9(0.9)$ & $10.6(1.3)$ \\
{$\left[\mathrm{B}\left(\mathrm{C}_{6} \mathrm{~F}_{5}\right)_{4}\right]^{-}$} & $10.6(2.4)$ & $8.8(1.0)$ & $6.8(0.7)$ \\
{$\left[\mathrm{B}\left\{3,5-\mathrm{C}_{6} \mathrm{H}_{3}\left(\mathrm{CF}_{3}\right)_{2}\right\}_{4}\right]^{-}$} & $22.7(2.4)$ & $21.5(2.4)$ & $26.2(2.5)$
\end{tabular}

${ }^{a}$ The supporting electrolyte represented here consists of a cation and an anion which can be found from the column name and row name respectively. ${ }^{b}$ Molar conductivity in units of $\mathrm{S} \mathrm{cm}^{2} \mathrm{~mol}^{-1} \cdot{ }^{c}$ The numbers in brackets represent the concentration of electrolytes in $\mathrm{mmol} \mathrm{dm}^{-3}$.

This is about an order of magnitude improvement over $\left[\mathrm{N}^{n} \mathrm{Bu}_{4}\right]\left[\mathrm{BF}_{4}\right]$. For a solution of $0.07 \mathrm{M} \quad\left[\mathrm{N}^{n} \mathrm{Bu}_{4}\right][\mathrm{B}\{3,5-$ $\left.\mathrm{C}_{6} \mathrm{H}_{3}\left(\mathrm{CF}_{3}\right)_{2}\right\}_{4}$ ] dissolved in $\mathrm{ScCO}_{2}-\mathrm{CH}_{3} \mathrm{CN}$ (molar ratio $\mathrm{CH}_{3} \mathrm{CN}$ : $\mathrm{CO}_{2} \sim 0.12$ ) at $20 \mathrm{MPa}$ and $328.15 \mathrm{~K}$ we obtain a maximum measured conductivity of $\sim 3 \mathrm{mS} \mathrm{cm}^{-1}$.

Studies of the conductivity as a function of concentration, Fig. 12, show an increase in molar conductivity with concentration for both $\left[\mathrm{N}^{n} \mathrm{Bu}_{4}\right]\left[\mathrm{B}\left\{3,5-\mathrm{C}_{6} \mathrm{H}_{3}\left(\mathrm{CF}_{3}\right)_{2}\right\}_{4}\right]$ and $\left[\mathrm{NR}^{\mathrm{f} n} \mathrm{Bu}_{3}\right]$ $\left[\mathrm{B}\left\{3,5-\mathrm{C}_{6} \mathrm{H}_{3}\left(\mathrm{CF}_{3}\right)_{2}\right\}_{4}\right]$. At low electrolyte concentrations, Kohlrausch's law predicts that the molar conductivity should decrease with increasing electrolyte concentration.

$$
\Lambda=\Lambda_{0}-A \sqrt{c}
$$

where $\Lambda$ is the molar conductivity, $\Lambda_{0}$ is the sum of the limiting molar conductivities of the single ions $\left(\mathrm{A}^{+}\right.$and $\left.\mathrm{B}^{-}\right), A$ is a constant and $c$ the concentration of the electrolyte.

However, for low dielectric constant solutions, such as supercritical fluids, the association of ions to form ion pairs and ion triples becomes significant. According to the Fuoss-Kraus model $^{80}$ the conductivity under these conditions is given by

$$
\Lambda=\frac{\Lambda_{0} \sqrt{K}}{\sqrt{c}}+\frac{\lambda_{0} \sqrt{K c}}{k}
$$

where $K$ is the equilibrium constant describing formation of the $\mathrm{AB}$ ion pairs, $\lambda_{0}$ is the sum of the limiting molar conductances of the two kinds of triple ions $\left(\mathrm{ABA}^{+}\right.$and $\left.\mathrm{BAB}^{-}\right)$and $k$ is the equilibrium constant describing the formation of the triple ions (assumed to be the same for both types of triple ion for simplicity). As we can see from Fig. 12 there is reasonable agreement between the data and the Fuoss-Kraus model at the lower electrolyte concentrations. The simple Fuoss-Kraus model of eqn (2) neglects the effects of the ion interactions on the conductivity (the electrophoretic and relaxation effects) and assumes that the activity coefficient is unity. More sophisticated treatments have been described in the literature that take these effects into account (see for example the work of Goldfarb and Corti $^{71}$ or Abbott and Schiffrin ${ }^{89}$ for applications of these) but these require values for the dielectric constant, viscosity or limiting molar conductivity which we do not have for this supercritical system. The results in Fig. 11 and 12 also show that the fluorous ponytail does not have a significant influence

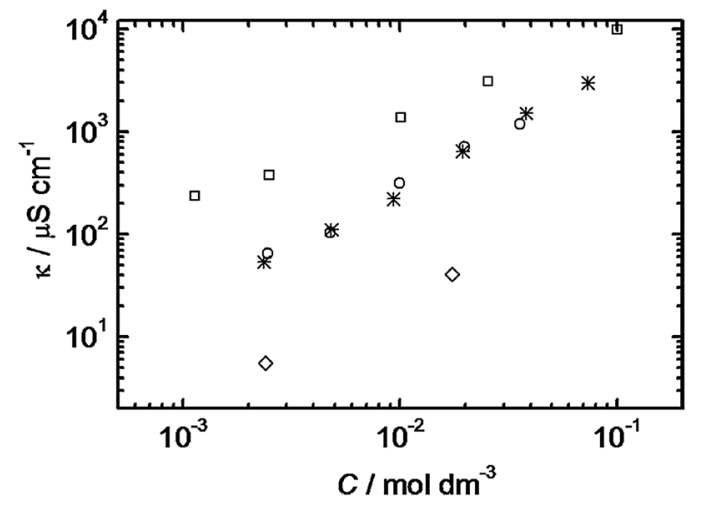

Fig. 11 Conductivity of different supercritical fluid electrolyte solutions. Electrical conductivity of supporting electrolytes in a supercritical fluid mixture of $\mathrm{CO}_{2}+\mathrm{CH}_{3} \mathrm{CN}\left(x_{\mathrm{CO}_{2}}: x_{\mathrm{CH}_{3} \mathrm{CN}}=0.89: 0.11\right)$ at $328.15 \mathrm{~K}$ and $20.0 \mathrm{MPa} . \diamond,\left[\mathrm{N}^{n} \mathrm{Bu}_{4}\right]\left[\mathrm{BF}_{4}\right] ;{ }^{*},\left[\mathrm{~N}^{n} \mathrm{Bu}_{4}\right]\left[\mathrm{B}\left\{3,5-\mathrm{C}_{6} \mathrm{H}_{3}\left(\mathrm{CF}_{3}\right)_{2}\right\}_{4}\right] ; \bigcirc,\left[\mathrm{NR}^{\mathrm{fn}} \mathrm{Bu}_{3}\right]-$ $\left[\mathrm{B}\left\{3,5-\mathrm{C}_{6} \mathrm{H}_{3}\left(\mathrm{CF}_{3}\right)_{2}\right\}_{4}\right] ; \square$, [N $\left.\mathrm{N}^{n} \mathrm{Bu}_{4}\right]\left[\mathrm{BF}_{4}\right]$ in pure $\mathrm{CH}_{3} \mathrm{CN}$ at ambient condition. ${ }^{5}$

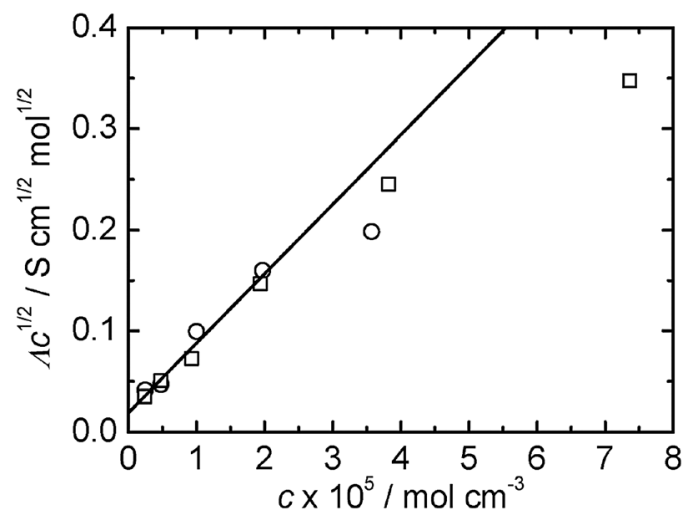

Fig. 12 Plot of $\Lambda \sqrt{c}$ against $c$ for the data shown in Fig. 11: ( $\square$ ) $\left[\mathrm{N}^{n} \mathrm{Bu}_{4}\right]-$ $\left[\mathrm{B}\left\{3,5-\mathrm{C}_{6} \mathrm{H}_{3}\left(\mathrm{CF}_{3}\right)_{2}\right\}_{4}\right]$; and $(\mathrm{O})\left[\mathrm{NR}^{\mathrm{fn}} \mathrm{Bu} u_{3}\right]\left[\mathrm{B}\left\{3,5-\mathrm{C}_{6} \mathrm{H}_{3}\left(\mathrm{CF}_{3}\right)_{2}\right\}_{4}\right]$. The line is the best fit to the low concentration (below $3 \times 10^{-5} \mathrm{~mol} \mathrm{~cm}^{-3}$ ) data. ${ }^{34}$

on the extent of ion pairing. From these experiments it is clear that triple ions make a significant contribution to conduction in $\mathrm{ScCO}_{2}-\mathrm{CH}_{3} \mathrm{CN}$.

We have carried out similar phase behaviour and conductivity studies for supercritical $\mathrm{CHF}_{3}, \mathrm{CH}_{2} \mathrm{~F}_{2}$, and $\mathrm{CH}_{2} \mathrm{FCF}_{3}$ containing $\quad\left[\mathrm{N}^{n} \mathrm{Bu}_{4}\right]\left[\mathrm{BF}_{4}\right], \quad\left[\mathrm{N}^{n} \mathrm{Bu}_{4}\right]\left[\mathrm{B}\left\{3,5-\mathrm{C}_{6} \mathrm{H}_{3}\left(\mathrm{CF}_{3}\right)_{2}\right\}_{4}\right]$ and $\mathrm{Na}\left[\mathrm{B}\left\{3,5-\mathrm{C}_{6} \mathrm{H}_{3}\left(\mathrm{CF}_{3}\right)_{2}\right\}_{4}\right]{ }^{52}$ As we can see from Table 3 these three hydrofluorocarbons have reasonably accessible critical temperatures and pressures and all have dipole moments greater than $1.6 \mathrm{D}$. Compared to the $\mathrm{CO}_{2}+\mathrm{CH}_{3} \mathrm{CN}$ system $\left(x_{\mathrm{CO}_{2}} / x_{\mathrm{CH}_{3} \mathrm{CN}}=0.14\right)$ discussed above, the pressures required to form a homogeneous solution for $\left[\mathrm{N}^{n} \mathrm{Bu}_{4}\right]\left[\mathrm{BF}_{4}\right]$ electrolyte are much lower (Fig. 13).

Table 3 Physical properties of some hydrofluorocarbons

\begin{tabular}{llll}
\hline Physical property & $\mathrm{CHF}_{3}$ & $\mathrm{CH}_{2} \mathrm{~F}_{2}$ & $\mathrm{CH}_{2} \mathrm{FCF}_{3}$ \\
\hline$T_{\mathrm{c}} / \mathrm{K}$ & 299.29 & 351.26 & 374.21 \\
$p_{\mathrm{c}} / \mathrm{MPa}$ & 4.832 & 5.782 & 4.049 \\
$\rho_{\mathrm{c}} / \mathrm{kg} \mathrm{m}^{-3}$ & 526.5 & 424.00 & 511.90 \\
$\mu / \mathrm{D}$ & 1.65 & $1.98 \pm 0.02$ & $1.80 \pm 0.22$
\end{tabular}




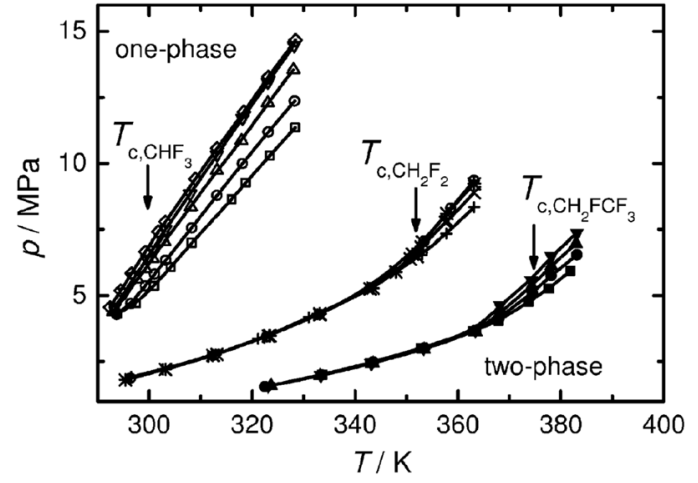

Fig. $13 p-T$ phase diagram of the mixture of $\left[\mathrm{N}^{n} \mathrm{Bu}_{4}\right]\left[\mathrm{BF} F_{4}\right](1)+\mathrm{HFC}$ (2). HFC $=\mathrm{CHF}_{3}: \square, x_{1}=0.82 \times 10^{-3} ; x_{1}=1.59 \times 10^{-3} ; \triangle, x_{1}=2.44 \times 10^{-3} ; \nabla, x_{1}=$ $4.83 \times 10^{-3} ; \diamond, x_{1}=6.90 \times 10^{-3} . \mathrm{HFC}=\mathrm{CH}_{2} \mathrm{~F}_{2}:+, x_{1}=1.67 \times 10^{-3} ; \times, x_{1}=$ $2.55 \times 10^{-3} ;{ }^{*}, x_{1}=3.29 \times 10^{-3} ; \oplus, x_{1}=4.17 \times 10^{-3} ; \mathrm{HFC}=\mathrm{CHF}_{2} \mathrm{CF}_{3}$ : $x_{1}=1.33 \times 10^{-3} ; \bullet, x_{1}=2.62 \times 10^{-3} ; \mathbf{\Lambda}, x_{1}=3.91 \times 10^{-3} ; \boldsymbol{\nabla}, x_{1}=5.14 \times 10^{-3}$ The arrows indicate the critical temperature of the HFCs. ${ }^{52}$

For all three HFCs we find that when the temperature is below the corresponding $T_{\mathrm{c}}$ (marked by the arrows in Fig. 13) the $p-T$ boundaries are overlapped for the mixtures with different composition of $\left[\mathrm{N}^{n} \mathrm{Bu}_{4}\right]\left[\mathrm{BF}_{4}\right]$ but at higher temperature the solubility of $\left[\mathrm{N}^{n} \mathrm{Bu}_{4}\right]\left[\mathrm{BF}_{4}\right]$ in the HFC fluid phase increases with increasing pressure. Although all three HFCs are good solvents for $\left[\mathrm{N}^{n} \mathrm{Bu}_{4}\right]\left[\mathrm{BF}_{4}\right], \mathrm{CH}_{2} \mathrm{~F}_{2}$ gives the lowest reduced pressure, $p_{\mathrm{r}}$ (where $p_{\mathrm{r}}=p / p_{\mathrm{c}, \mathrm{HFC}}$ the ratio of the pressure on the phase to the critical pressure of the corresponding HFC), for dissolving the same amount of $\left[\mathrm{N}^{n} \mathrm{Bu}_{4}\right]\left[\mathrm{BF}_{4}\right]$. This may be explained by the fact that $\mathrm{CH}_{2} \mathrm{~F}_{2}$ has the highest dipole moment of the three (Table 3).

Fig. 14 shows $p-T$ phase diagrams for three binary mixtures of $\mathrm{CH}_{2} \mathrm{~F}_{2}$ and three different electrolytes, $\left[\mathrm{N}^{n} \mathrm{Bu}_{4}\right]\left[\mathrm{BF}_{4}\right]$, $\left[\mathrm{N}^{n} \mathrm{Bu}_{4}\right]\left[\mathrm{B}\left\{3,5-\mathrm{C}_{6} \mathrm{H}_{3}\left(\mathrm{CF}_{3}\right)_{2}\right\}_{4}\right]$, and $\mathrm{Na}\left[\mathrm{B}\left\{3,5-\mathrm{C}_{6} \mathrm{H}_{3}\left(\mathrm{CF}_{3}\right)_{2}\right\}_{4}\right]$, at similar mole fraction $\left(x_{\text {electrolyte }}=\sim 1.65 \times 10^{-3}\right)$. The $p-T$ phase boundaries for all of the mixtures are almost superimposed with only a slight difference in the phase separation pressure observed when $T>353 \mathrm{~K}$. It is not surprising that two binary

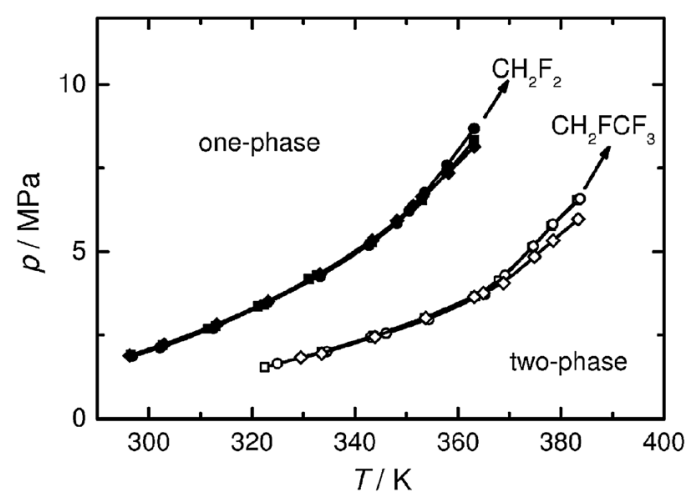

Fig. $14 p-T$ phase diagram of the mixtures of electrolyte (1) $+\mathrm{CH}_{2} \mathrm{~F}_{2}$ (2): $\mathbf{\square},\left[\mathrm{NBu}_{4}{ }_{4}\right]\left[\mathrm{BF}_{4}\right], x_{1}=1.67 \times 10^{-3} ; \bullet,\left[\mathrm{NBu}_{4}^{n}\right]\left[\mathrm{B}\left\{3,5-\mathrm{C}_{6} \mathrm{H}_{3}\left(\mathrm{CF}_{3}\right)_{2}\right\}_{4}\right], x_{1}=$ $1.65 \times 10^{-3} ; \bullet, \mathrm{Na}\left[\mathrm{B}\left\{3,5-\mathrm{C}_{6} \mathrm{H}_{3}\left(\mathrm{CF}_{3}\right)_{2}\right\}_{4}\right], x_{1}=1.62 \times 10^{-3}$; and of electrolyte (1) $+\mathrm{CHF}_{2} \mathrm{CF}_{3}$ (2): $\square,\left[\mathrm{NBu}_{4}^{n}\right]\left[\mathrm{BF}_{4}\right], x_{1}=2.62 \times 10^{-3} ; \mathrm{O},\left[\mathrm{NBu}_{4}^{n}\right]-$ $\left[\mathrm{B}\left\{3,5-\mathrm{C}_{6} \mathrm{H}_{3}\left(\mathrm{CF}_{3}\right)_{2}\right\}_{4}\right], x_{1}=2.58 \times 10^{-3} ; \diamond, \mathrm{Na}\left[\mathrm{B}\left\{3,5-\mathrm{C}_{6} \mathrm{H}_{3}\left(\mathrm{CF}_{3}\right)_{2}\right\}_{4}\right], x_{1}=$ $2.59 \times 10^{-3.52}$

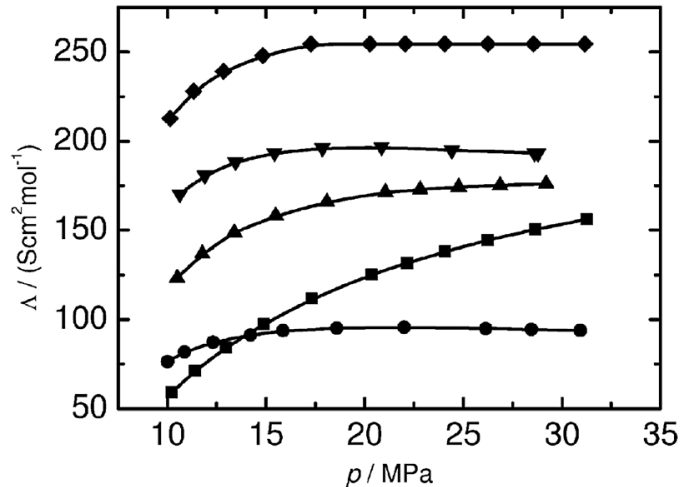

Fig. 15 Molar conductivity of the supporting electrolytes in $\mathrm{CH}_{2} \mathrm{~F}_{2}$ at $363.15 \mathrm{~K}$. The molar concentration of the electrolytes is $\sim 9.0 \mathrm{~mol} \mathrm{~m}^{-3}$. - $\left[\mathrm{N}^{n} \mathrm{Bu}_{4}\right]\left[\mathrm{BF} \mathrm{F}_{4}\right] ; \boldsymbol{O},\left[\mathrm{NR}^{\mathrm{fn}} \mathrm{Bu}_{3}\right]\left[\mathrm{B}\left\{3,5-\mathrm{C}_{6} \mathrm{H}_{3}\left(\mathrm{CF}_{3}\right)_{2}\right\}_{4}\right] ;\left[\mathrm{N}^{n} \mathrm{Bu}_{4}\right]\left[\mathrm{B}\left(\mathrm{C}_{6} \mathrm{~F}_{5}\right)_{4}\right]$; $\boldsymbol{\Delta},\left[\mathrm{N}^{n} \mathrm{Bu}_{4}\right]\left[\mathrm{B}\left\{3,5-\mathrm{C}_{6} \mathrm{H}_{3}\left(\mathrm{CF}_{3}\right)_{2}\right\}_{4}\right] ; \boldsymbol{\nabla}, \mathrm{Na}\left[\mathrm{B}\left\{3,5-\mathrm{C}_{6} \mathrm{H}_{3}\left(\mathrm{CF}_{3}\right)_{2}\right\}_{4}\right] ; \bullet, \mathrm{Na}[\mathrm{B}\{3,5-$ $\left.\left.\mathrm{C}_{6} \mathrm{H}_{3}\left(\mathrm{CF}_{3}\right)_{2}\right\}_{4}\right]^{52}$

mixtures with $\left[\mathrm{N}^{n} \mathrm{Bu}_{4}\right]\left[\mathrm{BF}_{4}\right]$ and $\left[\mathrm{N}^{n} \mathrm{Bu}_{4}\right]\left[\mathrm{B}\left\{3,5-\mathrm{C}_{6} \mathrm{H}_{3}\left(\mathrm{CF}_{3}\right)_{2}\right\}_{4}\right]$ show similar behaviour because $\mathrm{CH}_{2} \mathrm{~F}_{2}$ is such a good solvent for tetrabutylammonium salts and, consequently, the effect of replacing $\left[\mathrm{BF}_{4}\right]^{-}$by the $\left[\mathrm{B}\left\{3,5-\mathrm{C}_{6} \mathrm{H}_{3}\left(\mathrm{CF}_{3}\right)_{2}\right\}_{4}\right]^{-}$anion is not very significant. However, it is surprising that $\mathrm{Na}\left[\mathrm{B}\left\{3,5-\mathrm{C}_{6} \mathrm{H}_{3}\left(\mathrm{CF}_{3}\right)_{2}\right\}_{4}\right]$ shows such similar behaviour, given that sodium salts often have low solubility in organic solvents. Here it would appear that the $\left[\mathrm{B}\left\{3,5-\mathrm{C}_{6} \mathrm{H}_{3}\left(\mathrm{CF}_{3}\right)_{2}\right\}_{4}\right]^{-}$anion is a key component to enhance the solubility of $\mathrm{Na}\left[\mathrm{B}\left\{3,5-\mathrm{C}_{6} \mathrm{H}_{3}\left(\mathrm{CF}_{3}\right)_{2}\right\}_{4}\right]$ in $\mathrm{CH}_{2} \mathrm{~F}_{2}$, and the large size difference between $\mathrm{Na}^{+}$and $\left[\mathrm{B}\left\{3,5-\mathrm{C}_{6} \mathrm{H}_{3}\left(\mathrm{CF}_{3}\right)_{2}\right\}_{4}\right]^{-}$is probably important. Similar results are found for the same three supporting electrolytes in $\mathrm{CH}_{2} \mathrm{FCF}_{3}$ at a fixed mole fraction of $\sim 2.60 \times 10^{-3}$, also shown in Fig. 14 .

Studies of the conductivity of $\left[\mathrm{N}^{n} \mathrm{Bu}_{4}\right]\left[\mathrm{B}\left(\mathrm{C}_{6} \mathrm{~F}_{5}\right)_{4}\right],\left[\mathrm{N}^{n} \mathrm{Bu} \mathrm{u}_{4}\right]\left[\mathrm{B}\left\{3,5^{-}\right.\right.$ $\left.\left.\mathrm{C}_{6} \mathrm{H}_{3}\left(\mathrm{CF}_{3}\right)_{2}\right\}_{4}\right],\left[\mathrm{NR}^{\mathrm{f} n} \mathrm{Bu}_{3}\right]\left[\mathrm{B}\left\{3,5-\mathrm{C}_{6} \mathrm{H}_{3}\left(\mathrm{CF}_{3}\right)_{2}\right\}_{4}\right]\left(\mathrm{R}^{\mathrm{f}}=\left(\mathrm{CH}_{2}\right)_{3} \mathrm{C}_{7} \mathrm{~F}_{15}\right)$, and $\mathrm{Na}\left[\mathrm{B}\left\{3,5-\mathrm{C}_{6} \mathrm{H}_{3}\left(\mathrm{CF}_{3}\right)_{2}\right\}_{4}\right]$ in $\mathrm{scCH}_{2} \mathrm{~F}_{2}$, Fig. 15 and Table 4, show that these salts are more conducting than $\left[\mathrm{N}^{n} \mathrm{Bu}_{4}\right]\left[\mathrm{BF}_{4}\right]$ under the same conditions although the increase is much less significant than that for supercritical $\mathrm{CO}_{2}+\mathrm{CH}_{3} \mathrm{CN}$. Consequently, either $\left[\mathrm{N}^{n} \mathrm{Bu}_{4}\right]\left[\mathrm{BF}_{4}\right]$ or the corresponding $\left[\mathrm{B}\left(\mathrm{Ar}^{\mathrm{F}}\right)_{4}\right]^{-}$salts are good choices for supporting electrolytes for electrodeposition from $\mathrm{ScCH}_{2} \mathrm{~F}_{2}$.

Typical conductivities for $1 \mathrm{M}$ electrolyte solutions in acetonitrile ${ }^{90}$ are in the range $20-55 \mathrm{~S} \mathrm{~cm}^{2} \mathrm{~mol}^{-1}$ so the values we obtain for the supercritical fluids are quite respectable for a

Table 4 Molar conductivity of the supporting electrolytes in $\mathrm{CH}_{2} \mathrm{~F}_{2}$ at $363 \mathrm{~K}$ and $20 \mathrm{MPa}$. The concentration of all the electrolytes is $\sim 9.0 \mathrm{~mol} \mathrm{~m}^{-3}$. Piecewise cubic Hermite polynomials were used to interpolate the data shown in Fig. 15 to the fixed pressure (20 MPa)

\begin{tabular}{lc}
\hline Electrolyte & $\Lambda / \mathrm{S} \mathrm{cm}^{2} \mathrm{~mol}^{-1}$ \\
\hline$\left[\mathrm{N}^{n} \mathrm{Bu}_{4}\right]\left[\mathrm{BF}_{4}\right]$ & 124 \\
{$\left[\mathrm{NR}^{\mathrm{fn}} \mathrm{Bu}_{3}\right]\left[\mathrm{B}\left\{3,5-\mathrm{C}_{6} \mathrm{H}_{3}\left(\mathrm{CF}_{3}\right)_{2}\right\}_{4}\right]^{a}$} & 95 \\
{$\left[\mathrm{~N}^{n} \mathrm{Bu}_{4}\right]\left[\mathrm{B}\left(\mathrm{C}_{6} \mathrm{~F}_{5}\right)_{4}\right]$} & 170 \\
{$\left[\mathrm{~N}^{n} \mathrm{Bu}_{4}\right]\left[\mathrm{B}\left\{3,5-\mathrm{C}_{6} \mathrm{H}_{3}\left(\mathrm{CF}_{3}\right)_{2}\right\}_{4}\right]$} & 197 \\
$\mathrm{Na}\left[\mathrm{B}\left\{3,5-\mathrm{C}_{6} \mathrm{H}_{3}\left(\mathrm{CF}_{3}\right)_{2}\right\}_{4}\right]$ & 255
\end{tabular}

${ }^{a} \mathrm{R}^{\mathrm{f}}=\mathrm{CF}_{3}\left(\mathrm{CF}_{2}\right)_{7}\left(\mathrm{CH}_{2}\right)_{3} \cdot{ }^{52}$ 
non-aqueous electrolyte and sufficient to carry out electrochemical studies.

\section{Reagents}

The reagents used in SCFED also require a number of key properties. In addition to solubility in the SCF, they need to be both stable to the electrolyte and at the working temperature, and ideally readily synthesised in high purity. Unwanted electrochemical side reactions which could result in fouling of the electrode or counter-electrode by the reagents and reactive liberated ligands must also be avoided. For example, $[\mathrm{Ag}(\operatorname{cod})(\mathrm{hfac})] \mathrm{BF}_{4}(\operatorname{cod}=$ cyclooctadiene; hfac $=$ hexafluoroacetylacetonyl) is unsuitable for $\mathrm{Ag}$ deposition, probably because the cod fouls the counter electrode, whilst if $\left[\mathrm{Cu}(\mathrm{hfac})_{2}\right]$ is used for copper deposition in $\mathrm{scCO}_{2}-\mathrm{CH}_{3} \mathrm{CN}$ the deposited copper can redissolve due to the reaction ${ }^{91}$

$$
\left[\mathrm{Cu}(\mathrm{hfac})_{2}\right]+\mathrm{Cu}+8 \mathrm{CH}_{3} \mathrm{CN} \rightarrow 2\left[\mathrm{Cu}\left(\mathrm{CH}_{3} \mathrm{CN}\right)_{4}\right]^{+}+2 \mathrm{hfac}^{-}
$$

For deposition of transition metals from $\mathrm{scCO}_{2}-\mathrm{CH}_{3} \mathrm{CN}$ the nitrile complexes $\left[\mathrm{M}\left(\mathrm{CH}_{3} \mathrm{CN}\right)_{x}\right]\left[\mathrm{BF}_{4}\right]_{n}(\mathrm{M}=\mathrm{Fe}, \mathrm{Co}, \mathrm{Cu}, \mathrm{Ag}$, etc. $)$ are attractive reagents since the anion can be present in the electrolyte and the deposition liberates $\mathrm{CH}_{3} \mathrm{CN}$ which is present as co-solvent, hence no chemical incompatibilities are presented. ${ }^{5,91}$ However in $\mathrm{scCH}_{2} \mathrm{~F}_{2}$, the complexes are unstable in the absence of added $\mathrm{CH}_{3} \mathrm{CN}$, which limits their usefulness, whilst $\left[\mathrm{Cu}(\mathrm{hfac})_{2}\right]$ is stable in $\mathrm{scCH}_{2} \mathrm{~F}_{2}{ }^{52}$ The nitrile complexes are readily made from the metal powders and $\mathrm{NO}\left[\mathrm{BF}_{4}\right]$ in $\mathrm{CH}_{3} \mathrm{CN}{ }^{92,93}$ In the case of $\mathrm{Cu}(\mathrm{I})$, $\left[\mathrm{Cu}\left(\mathrm{CH}_{3} \mathrm{CN}\right)_{4}\right]\left[\mathrm{BF}_{4}\right]$ is obtainable from $\mathrm{Cu}_{2} \mathrm{O}$ and aqueous $\mathrm{HBF}_{4}$ in $\mathrm{CH}_{3} \mathrm{CN}$, or by refluxing $\mathrm{Cu}\left[\mathrm{BF}_{4}\right]_{2}$ with copper in $\mathrm{CH}_{3} \mathrm{CN}$. ${ }^{94}$ The nitrile complexes can also be converted to $\left[\mathrm{B}\left(\mathrm{Ar}^{\mathrm{F}}\right)_{4}\right]^{-}$salts to increase solubility in the SCF if required. ${ }^{92,93}$ For silver electrodeposition several reagents were considered for use in $\mathrm{scCO}_{2}-\mathrm{CH}_{3} \mathrm{CN}$ including [Ag(hfac)(cod)], $\left[\mathrm{Ag}\left(\mathrm{CH}_{3} \mathrm{CN}\right)_{4}\right]\left[\mathrm{BF}_{4}\right]$, and $\left[\mathrm{CF}_{3}\left(\mathrm{CF}_{2}\right)_{6} \mathrm{CO}_{2} \mathrm{Ag}\left(\mathrm{PPh}_{3}\right)_{2}\right]$ and $\left[\mathrm{Ag}\left(\mathrm{PPh}_{3}\right)_{4}\right]\left[\mathrm{BF}_{4}\right]$, in which the arylphosphine groups and the perfluorocarboxylate ligand were introduced to increase solubility in hydrofluorocarbons. Of these, $\left[\mathrm{Ag}\left(\mathrm{CH}_{3} \mathrm{CN}\right)_{4}\right]\left[\mathrm{BF}_{4}\right]$ was found to be the most suitable for silver deposition from $\mathrm{scCO}_{2}-\mathrm{CH}_{3} \mathrm{CN}$ (see below). ${ }^{95}$

The choice of reagents to electrodeposit germanium is less obvious than for copper or silver. Germanium forms compounds in two oxidation states, $\mathrm{Ge}(\mathrm{II})$ and $\mathrm{Ge}(\mathrm{Iv})$, and the chemical stability of its compounds varies widely with the ligands present. ${ }^{6,96}$ Many Ge(Iv) complexes are moisture sensitive, whilst the thermal stability of $\mathrm{Ge}$ (II) complexes is often poor. Among the $\mathrm{Ge}(\mathrm{II})$ complexes explored were the commercially available $\mathrm{GeBr}_{2}$, a complex of the functionalised diimine $\left[\mathrm{GeCl}_{2}\left(4,4^{\prime}\right.\right.$-didecyl-2,2'bipyridyl)], ${ }^{6}$ the trichlorogermanate(II) salt $\left[\mathrm{N}^{n} \mathrm{Bu}_{4}\right]\left[\mathrm{GeCl}_{3}\right]$, made by reduction of $\mathrm{GeCl}_{4}$ in aqueous hydrochloric acid with $\mathrm{H}_{3} \mathrm{PO}_{2}$, followed by addition of $\left[\mathrm{N}^{n} \mathrm{Bu}_{4}\right] \mathrm{Cl},{ }^{6}$ and [ $\mathrm{Ge}(12$-crown$\left.4)_{2}\right]\left[\mathrm{CF}_{3} \mathrm{SO}_{3}\right]_{2}$, made from $\left[\mathrm{GeCl}_{2}\right.$ (dioxane) $]$ and 12-crown-4. The first two proved to be too poorly soluble in $\mathrm{scCH}_{2} \mathrm{~F}_{2}$, and whilst it was soluble, $\left[\mathrm{Ge}(12 \text {-crown-4 })_{2}\right]\left[\mathrm{CF}_{3} \mathrm{SO}_{3}\right]_{2}$ degraded in the same solvent. ${ }^{6}\left[\mathrm{~N}^{n} \mathrm{Bu}_{4}\right]\left[\mathrm{GeCl}_{3}\right]$ was both soluble and stable in $\mathrm{scCH}_{2} \mathrm{~F}_{2}$ and its electrochemistry is described below. Among the Ge(rv) reagents assessed were $\left[\mathrm{GeF}_{4}\left(\mathrm{CH}_{3} \mathrm{CN}\right)_{2}\right]$, made by passing $\mathrm{GeF}_{4}$ gas into dry $\mathrm{CH}_{3} \mathrm{CN}$, and $\left[\mathrm{GeF}_{4}\left(\mathrm{Me}_{2} \mathrm{NCH}_{2} \mathrm{CH}_{2} \mathrm{NMe}_{2}\right)\right]$, prepared from $\left[\mathrm{GeF}_{4}\left(\mathrm{CH}_{3} \mathrm{CN}\right)_{2}\right]$ and $\mathrm{Me}_{2} \mathrm{NCH}_{2} \mathrm{CH}_{2} \mathrm{NMe}_{2}$ in $\mathrm{CH}_{2} \mathrm{Cl}_{2} \cdot{ }^{97}$ These two reagents were chosen as they are thermally relatively stable, and since they are coordinatively saturated, they are moisture stable solids and relatively resistant to hydrolysis in solution. Unfortunately, they proved to be insufficiently soluble in the SCFs. As a non-polar liquid, $\mathrm{GeCl}_{4}$ (B.P. $365 \mathrm{~K}$ ) was expected to be readily miscible with SCFs, but it is moisture sensitive and readily hydrolysed. It is commercially available and easily dried and purified by distillation from a mixture of $\mathrm{Na}_{2} \mathrm{CO}_{3}$ and $\mathrm{CaH}_{2}$.

\section{Electrodeposition}

There is very little published work on electrodeposition from supercritical fluids. As described above, the earliest work is probably that of Williams and Naiditch ${ }^{54}$ in 1976 and the work of Silvestri et al. ${ }^{55}$ five years later. Finally, MacDonald et al. ${ }^{62}$ in 1986 reported deposition of $\mathrm{Cu}$ from $\mathrm{CuCl}_{2}$ under supercritical, or close to supercritical, $\mathrm{H}_{2} \mathrm{O}$ containing $\mathrm{KCl}$ at $573 \mathrm{~K}$ and 8.2 MPa. Apart from the three papers on electrodeposition of metals there are also a few papers which describe the electrodeposition of conducting polymers from supercritical fluids. This is slightly different because in this case the neutral solution species (the heterocyclic monomer) is oxidised to produce a charged product (the oxidised polymer) which deposits with the counter ion on the electrode surface. The first paper claiming to electrodeposit poly(pyrrole) and poly(aniline) from a supercritical fluid appeared in 2002. ${ }^{98}$ This group used $\mathrm{CO}_{2}$ containing $13.1 \%$ acetonitrile, $0.16 \mathrm{M}$ pyrrole and $0.16 \mathrm{M}\left[\mathrm{N}^{n} \mathrm{Bu}_{4}\right]\left[\mathrm{PF}_{6}\right]$ at $323 \mathrm{~K}$ and 9.65 MPa. Subsequent work published in 2005 by Yan et al. ${ }^{99}$ using a view cell showed that under these conditions the system was biphasic and not in the supercritical state. Yan et al. were, however, able to deposit poly(pyrrole) films from supercritical fluid using $\mathrm{CO}_{2}$ containing $13.1 \%$ acetonitrile, $0.16 \mathrm{M}$ pyrrole and $0.04 \mathrm{M}\left[\mathrm{N}^{n} \mathrm{Bu}_{4}\right]\left[\mathrm{PF}_{6}\right]$ at $323 \mathrm{~K}$ and $10 \mathrm{MPa}$. This illustrates one of the potential pitfalls of working with, or trying to work with, supercritical fluids. It is not sufficient to rely on the critical temperature and critical pressure of the pure fluid, but rather it is essential to properly characterise the phase behaviour of the whole system. The honour of reporting the first successful electropolymerisation of a conducting polymer from a supercritical fluid consequently falls to Atobe et al. ${ }^{100}$ who, in 2004, reported the electropolymerisation of poly(pyrrole) and poly(thiophene) from $\mathrm{scCHF}_{3}$ containing $10 \mathrm{mM}$ pyrrole or thiophene with $40 \mathrm{mM}$ $\left[\mathrm{N}^{n} \mathrm{Bu}_{4}\right]\left[\mathrm{PF}_{6}\right]$ at $323 \mathrm{~K}$ and $15 \mathrm{MPa}$.

Before moving on to discuss our recent work, it is appropriate to mention the work of Sone's group on electrodeposition from dense emulsions of $\mathrm{CO}_{2}$. The group has published extensively, starting in $2002,{ }^{101}$ on the electrodeposition of $\mathrm{Ni}$ from a dense emulsion of an aqueous Ni plating (Watts) bath formed in $\mathrm{scCO}_{2}$ using surfactants (typical conditions $323 \mathrm{~K}$ and $15 \mathrm{MPa}$ and $60 \mathrm{vol} \%$ of the aqueous plating bath stabilised with $1 \mathrm{vol} \%$ surfactant). ${ }^{102}$ This is not a single phase supercritical fluid. The advantages of the system 


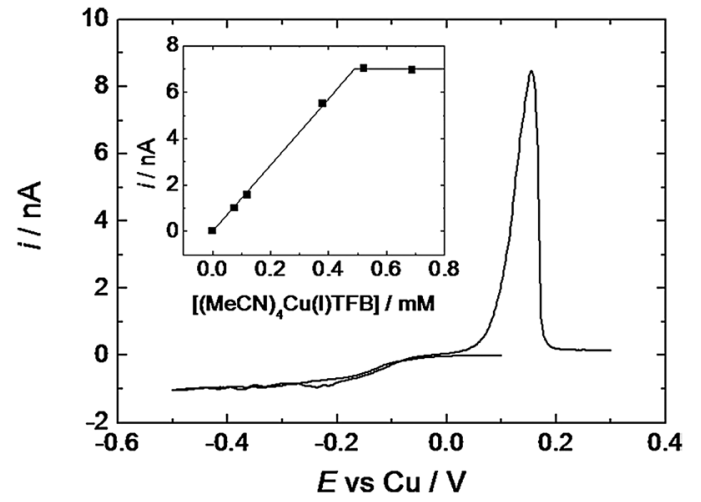

Fig. 16 Copper voltammetry performed in $\mathrm{scCO}_{2}$ with $12.1 \mathrm{wt} \% \mathrm{CH}_{3} \mathrm{CN}$ and $\left[\mathrm{N}^{n} \mathrm{Bu}\right]_{4}\left[\mathrm{BF}_{4}\right](20 \mathrm{mM})$; at $310 \mathrm{~K}$ and 17.24 MPa. Electrodes were: $25 \mu \mathrm{m}$ diameter platinum disc working electrode, $0.5 \mathrm{~mm}$ diameter platinum disc pseudo reference, and $0.5 \mathrm{~mm}$ diameter platinum wire counter electrode. The sweep rate was $20 \mathrm{mV} \mathrm{s}^{-1}$. The insert shows the limiting current as a function of the concentration of the copper complex. ${ }^{5}$

are that it produces high quality Ni films with higher uniformity, smaller (sub $100 \mathrm{~nm}$ ) grain size and significantly higher Vickers hardness than conventional electroplating from aqueous solution. ${ }^{103}$ This is attributed, at least in part, to the enhanced desorption of hydrogen gas bubbles during deposition. ${ }^{104}$ The same group has also applied this approach to the deposition of poly(pyrrole $)^{105}$ and copper. ${ }^{106}$

In our work we have studied the electrodeposition of copper from supercritical fluids. ${ }^{5,91}$ Fig. 16 shows cyclic voltammetry for $\left[\mathrm{Cu}\left(\mathrm{CH}_{3} \mathrm{CN}\right)_{4}\right]\left[\mathrm{BF}_{4}\right]$ in $\mathrm{scCO}_{2}-\mathrm{CH}_{3} \mathrm{CN}$ with $\left[\mathrm{N}^{n} \mathrm{Bu}_{4}\right]\left[\mathrm{BF}_{4}\right]$ electrolyte. The voltammetry shows the characteristic features expected for electrodeposition with mass transport limited reduction of $\mathrm{Cu}(\mathrm{I})$ to $\mathrm{Cu}(0)$ at negative potentials, accompanied by a stripping peak for $\mathrm{Cu}$ on the return scan. The stripping peak is sharp and undistorted, showing that $i R$ drop is insignificant in these experiments. The inset in Fig. 16 shows a plot of the mass transport limited currents recorded at a microdisc electrode for different concentrations of $\left[\mathrm{Cu}\left(\mathrm{CH}_{3} \mathrm{CN}\right)_{4}\right]\left[\mathrm{BF}_{4}\right]$ added to the solution. This is a very sensitive way to determine the solubility of the redox active species since the mass transport limiting current at the microdisc is given by

$$
I_{\mathrm{L}}=4 n F a D c
$$

where $n$ is the number of electrons transferred and $a$ is the radius of the microdisc electrode. Thus, assuming the diffusion coefficient, $D$, does not change with concentration, the limiting current should be proportional to the concentration of species dissolved in the solution. From the inset in Fig. 16 we can see that at low concentrations the current increases linearly with the concentration, as expected, but then abruptly reaches a plateau value, indicating that the solution is saturated. From the intersection of the two lines we obtain an estimate of the solubility of $\left[\mathrm{Cu}\left(\mathrm{CH}_{3} \mathrm{CN}\right)_{4}\right]\left[\mathrm{BF}_{4}\right]$ under these conditions of $0.49 \mathrm{mM}$. From the slope of the initial part of the curve, using the microdisc equation (eqn (4)), we obtain a diffusion coefficient of $3.5 \times 10^{-5} \mathrm{~cm}^{2} \mathrm{~s}^{-1}$. This is approximately 1.6 times larger than the value measured for the same complex in acetonitrile at $311 \mathrm{~K}$ $\left(2.2 \times 10^{-5} \mathrm{~cm}^{2} \mathrm{~s}^{-1}\right)$.
By changing the counter anion from $\left[\mathrm{BF}_{4}\right]^{-}$to $\left[\mathrm{B}\left\{3,5-\mathrm{C}_{6} \mathrm{H}_{3}-\right.\right.$ $\left.\left.\left(\mathrm{CF}_{3}\right)_{2}\right\}_{4}\right]^{-}$it is possible to significantly increase ( $>30$ times) the solubility of $\left[\mathrm{Cu}\left(\mathrm{CH}_{3} \mathrm{CN}\right)_{4}\right]^{+}$in $\mathrm{scCO}_{2}-\mathrm{CH}_{3} \mathrm{CN}$. This illustrates a significant advantage of careful choice and design of the electrolyte to enhance electrodeposition from supercritical fluids, the higher solubility of the reagent allows a greater rate of metal plating. For $\left[\mathrm{Cu}\left(\mathrm{CH}_{3} \mathrm{CN}\right)_{4}\right]^{+}$in supercritical $\mathrm{CO}_{2}$ with $12.1 \mathrm{wt} \%$ $\mathrm{CH}_{3} \mathrm{CN}$ and $20 \mathrm{mM}\left[\mathrm{N}^{n} \mathrm{Bu}_{4}\right]\left[\mathrm{B}\left\{3,5-\mathrm{C}_{6} \mathrm{H}_{3}\left(\mathrm{CF}_{3}\right)_{2}\right\}_{4}\right]$ electrolyte at $310-311 \mathrm{~K}$ the diffusion coefficient is $3.3 \times 10^{-5} \mathrm{~cm}^{2} \mathrm{~s}^{-1}$. This is $\sim 1.5$ times larger than the corresponding value in $\mathrm{scCO}_{2}-\mathrm{CH}_{3} \mathrm{CN}$ with $20 \mathrm{mM}\left[\mathrm{N}^{n} \mathrm{Bu}_{4}\right]\left[\mathrm{BF}_{4}\right]$, suggesting that there may be less ion pairing between the copper and the large $\left[\mathrm{B}\left\{3,5-\mathrm{C}_{6} \mathrm{H}_{3}\left(\mathrm{CF}_{3}\right)_{2}\right\}_{4}\right]^{-}$ion, leading to higher ion mobility. It is worth noting that these diffusion coefficients are relatively low compared to values for complexes dissolved in supercritical $\mathrm{CO}_{2} \cdot{ }^{107}$ This is probably due to the addition of $12-13 \mathrm{wt} \%$ acetonitrile as a co-solvent which significantly increases the viscosity of the solution. ${ }^{108,109}$

Using $\left[\mathrm{Cu}\left(\mathrm{CH}_{3} \mathrm{CN}\right)_{4}\right]^{+}$in $\mathrm{scCO}_{2}-\mathrm{CH}_{3} \mathrm{CN}$ it is possible to electroplate smooth, reflective copper films onto $1 \mathrm{~cm}^{2}$ electrodes. Fig. 17 shows SEM images of films deposited at different potentials. The morphology of the deposits varies with the applied potential as expected. At high overpotentials, when the deposition is mass transport limited, the films are rough and dendritic, whereas at low overpotentials the films are smooth, shiny and adherent. EDX, SIMS, and Auger studies all show that the films are high purity copper. Four-point probe measurements gave film resistivities for the best films of $4 \times 10^{-6} \Omega \mathrm{cm}$, which is comparable to values reported for copper electrodeposition from aqueous solution (1.75 to $2 \times 10^{-6} \Omega \mathrm{cm}$ depending on plating bath additives ${ }^{110}$ ) or by chemical deposition in supercritical $\mathrm{CO}_{2}$ as reported by Watkins et al. ${ }^{111}\left(2 \times 10^{-6} \Omega \mathrm{cm}\right)$. Thus the quality of the electrodeposited films is high and already close to that required for device applications.

An important feature of the copper plating bath described above is that it uses the $\mathrm{Cu}(\mathrm{I})$ complex. The relative stability of the $\mathrm{Cu}(\mathrm{I})$ and $\mathrm{Cu}(\mathrm{II})$ redox states strongly depends on the choice
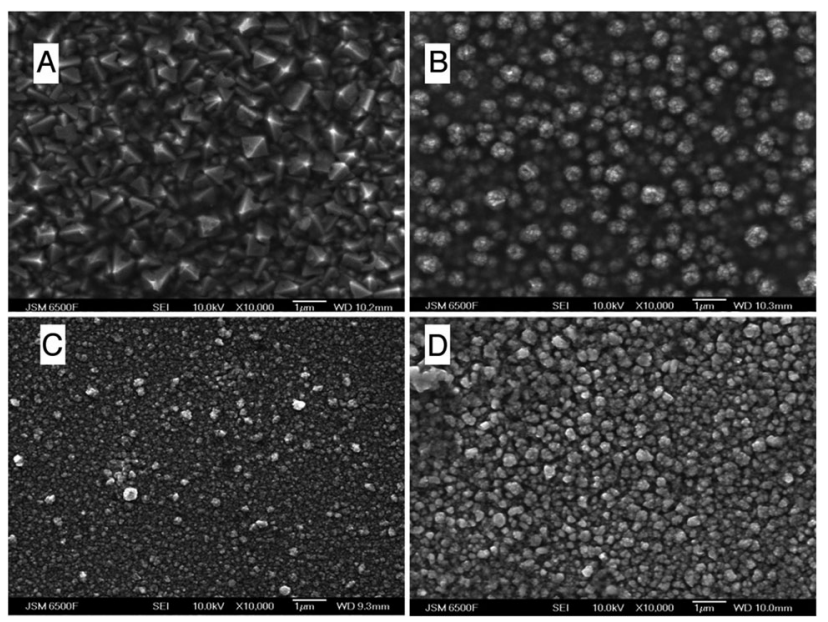

Fig. 17 Electroplated copper SEM images of copper films deposited from a saturated solution of $\left[\mathrm{Cu}\left(\mathrm{CH}_{3} \mathrm{CN}\right)_{4}\right] \mathrm{BF}_{4}$ in $87.4 \mathrm{wt} \% \mathrm{CO}_{2}, 12 \mathrm{wt} \%$ acetonitrile, $0.6 \mathrm{wt} \%\left[\mathrm{~N}^{n} \mathrm{Bu}_{4}\right]\left[\mathrm{BF}_{4}\right] 309-311 \mathrm{~K}$ and $13.8 \mathrm{MPa}$ at $(\mathrm{A})-0.6 \mathrm{~V}$, (B) $-0.9 \mathrm{~V}$, (C) $-1.5 \mathrm{~V}$, and (D) $-1.7 \mathrm{~V}$ vs. Pt. ${ }^{5}$ 


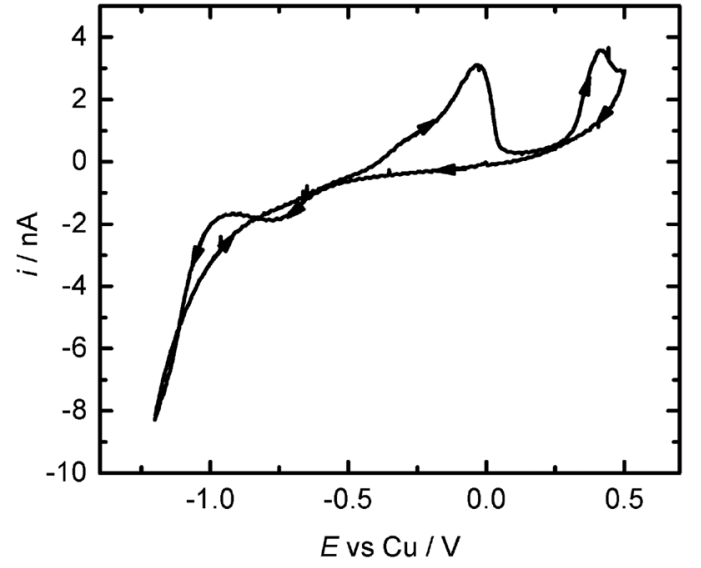

Fig. 18 Cyclic voltammetry for $1.2 \mathrm{mM}\left[\mathrm{Cu}(\mathrm{hfac})_{2}\right]$ in supercritical $\mathrm{CO}_{2}$ with 12.1 wt\% $\mathrm{CH}_{3} \mathrm{CN}$ containing $20 \mathrm{mM}\left[\mathrm{N}^{n} \mathrm{Bu}_{4}\right]\left[\mathrm{BF}_{4}\right]$ electrolyte. $T=$ $310 \mathrm{~K} . p=17.2 \mathrm{MPa}$. The working electrode was a $25 \mu \mathrm{m}$ diameter platinum disc, the counter electrode was a platinum grid and the reference a $0.5 \mathrm{~mm}$ polished copper disc. Sweep rate $20 \mathrm{mV} \mathrm{s}^{-1} .50$

of ligands. For $\left[\mathrm{Cu}\left(\mathrm{CH}_{3} \mathrm{CN}\right)_{4}\right]^{+}$the redox potential for oxidation to $\left[\mathrm{Cu}\left(\mathrm{CH}_{3} \mathrm{CN}\right)_{4}\right]^{2+}$ is high $\left(>1.25 \mathrm{~V}\right.$ vs. $\mathrm{Cu}$ in $\left.\mathrm{CH}_{3} \mathrm{CN}\right)$. It is possible to electroplate copper from the $\left[\mathrm{Cu}(\mathrm{hfac})_{2}\right]$ from $\mathrm{ScCO}_{2}-\mathrm{CH}_{3} \mathrm{CN}$, Fig. 18. Now however the comproportionation reaction, eqn (3), complicates the process so that this is not a good choice of reagent in this case. EDX analyses of these films shows contamination with fluorine and carbon.

We have also electrodeposited copper from supercritical hydrofluorocarbons. Studies of the phase behaviour of $\mathrm{CH}_{2} \mathrm{~F}_{2}$ containing $\left[\mathrm{N}^{n} \mathrm{Bu}_{4}\right]\left[\mathrm{BF}_{4}\right]$ and $\left[\mathrm{Cu}\left(\mathrm{CH}_{3} \mathrm{CN}\right)_{4}\right]\left[\mathrm{BF}_{4}\right]$ showed that the copper complex was unstable in the absence of added $\mathrm{CH}_{3} \mathrm{CN}^{52}$ Consequently, a small amount of $\mathrm{CH}_{3} \mathrm{CN}$ was added to the $\mathrm{CH}_{2} \mathrm{~F}_{2}$ not only to increase the solubility of $\left[\mathrm{Cu}\left(\mathrm{CH}_{3} \mathrm{CN}\right)_{4}\right]\left[\mathrm{BF}_{4}\right]$, but also to stabilise it. Phase behaviour studies show that addition of $\left[\mathrm{N}^{n} \mathrm{Bu}_{4}\right]\left[\mathrm{BF}_{4}\right]$ to the $\left[\mathrm{Cu}\left(\mathrm{CH}_{3} \mathrm{CN}\right)_{4}\right]\left[\mathrm{BF}_{4}\right]$ system in $\mathrm{scCH}_{2} \mathrm{~F}_{2}$ drastically shifts the phase boundary to high pressures at $T>$ $T_{\mathrm{c}, \mathrm{CH}_{2} \mathrm{~F}_{2}} \cdot{ }^{52}$ We believe that this is caused by selective solvation of the $\left[\mathrm{N}^{n} \mathrm{Bu}_{4}\right]^{+}$and $\left[\mathrm{BF}_{4}\right]^{-}$ions by $\mathrm{CH}_{3} \mathrm{CN}$, depleting the $\mathrm{CH}_{3} \mathrm{CN}$ molecules in the bulk phase, so that the density, and hence the pressure of the system, needs to be increased considerably for the quaternary mixture to form a homogeneous phase. Again this illustrates the importance of carefully characterising the phase behaviour of the electrolyte system.

$\left[\mathrm{Cu}(\mathrm{hfac})_{2}\right]$ is more soluble and more stable than $\left[\mathrm{Cu}\left(\mathrm{CH}_{3} \mathrm{CN}\right)_{4}\right]$ $\left[\mathrm{BF}_{4}\right]$ in $\mathrm{scCHF}_{3}$ and it only increases the phase-separation pressure by a moderate amount when added to the $\mathrm{CHF}_{3}$ solution with $\left[\mathrm{N}^{n} \mathrm{Bu}_{4}\right]\left[\mathrm{BF}_{4}\right]$ as the supporting electrolyte. ${ }^{91}$ Fig. 19 shows a cyclic voltammogram of $\left[\mathrm{Cu}(\mathrm{hfac})_{2}\right]$ in $\mathrm{scCHF}_{3}$ with free hfacH ligand added to the solution. The voltammetry is similar to that in $\mathrm{CH}_{3} \mathrm{CN}$ and in $\mathrm{ScCO}_{2}-\mathrm{CH}_{3} \mathrm{CN}$, with the $\left[\mathrm{Cu}(\mathrm{hfac})_{2}\right]$ reduced to metallic copper in one step. In this case there is a significant cathodic background current beyond -0.7 V. Deposition onto large area $\left(\sim 1 \mathrm{~cm}^{2}\right)$ electrodes was found to give good copper films with resistivities as low as $5.8 \times 10^{-6} \Omega \mathrm{cm}$. The best films were obtained with stirring and in the presence of the free ligand (hfacH).

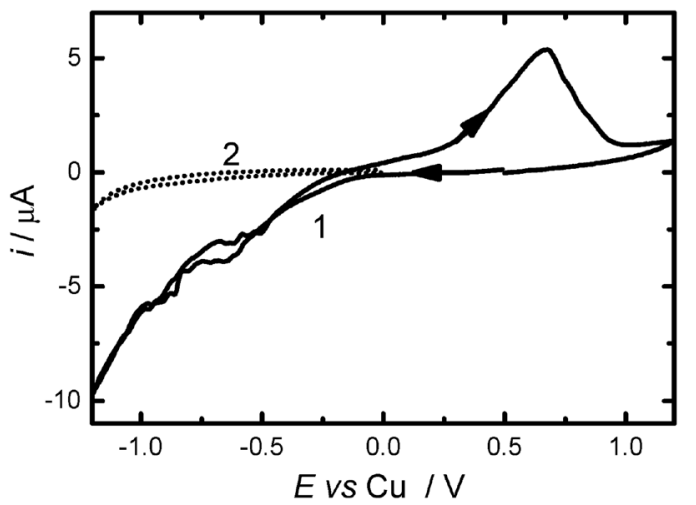

Fig. 19 Scan 1, cyclic voltammetry for $5.3 \mathrm{mM}\left[\mathrm{Cu}(\mathrm{hfac})_{2}\right]$ in $\mathrm{ScCHF}_{3}$ with $20 \mathrm{mM}\left[\mathrm{N}^{n} \mathrm{Bu}_{4}\right]\left[\mathrm{BF}_{4}\right]$ and $0.1 \mathrm{M} \mathrm{hfacH}$ at $311 \mathrm{~K}$ and $17 \mathrm{MPa}$. Scan 2 shows the background current in the absence of the $\mathrm{Cu}$ complex. The working electrode was a $0.37 \mathrm{~mm}$ diameter platinum disc, and the counter and reference electrodes were $0.5 \mathrm{~mm}$ diameter copper wires. Sweep rate $100 \mathrm{mV} \mathrm{s}^{-1}$. 0

We have also studied the electrodeposition of silver from $\mathrm{scCO}_{2}-\mathrm{CH}_{3} \mathrm{CN}$. ${ }^{95}$ Five silver reagents were investigated. Of these the most suitable was found to be $\left[\mathrm{Ag}\left(\mathrm{CH}_{3} \mathrm{CN}\right)_{4}\right]\left[\mathrm{BF}_{4}\right]$ which gives good quality metallic deposits without any complicating electrochemical reactions. Of the other complexes [Ag(hfac)(cod)] was found to give silver deposits, but polymerisation of the cod ligand on the counter electrode caused problems, and the silver deposition from $\left[\mathrm{CF}_{3}\left(\mathrm{CF}_{2}\right)_{6} \mathrm{CO}_{2} \mathrm{Ag}\left(\mathrm{PPh}_{3}\right)_{2}\right],\left[\mathrm{Ag}(\mathrm{hfac})\left(\mathrm{PPh}_{3}\right)\right]$ and $\left[\mathrm{Ag}\left(\mathrm{PPh}_{3}\right)_{4}\right]\left[\mathrm{BF}_{4}\right]$ were all accompanied by electrochemical reduction of the $\mathrm{PPh}_{3}$ ligand leading to a complex set of reactions with the electrolyte.

To exploit supercritical fluid electrodeposition to make devices it will be necessary to electrodeposit not only simple metals but also functional materials such as semiconductors. Germanium is an extremely important material in a wide range of technologies and single crystalline SiGe layers are widely used in integrated "silicon" electronics. ${ }^{112}$ Electrodeposition of nanostructured germanium would offer a number of advantages over other deposition techniques if sufficient material quality could be achieved. In addition, electrodeposition of germanium is a stepping stone to the electrodeposition of silicon-germanium and silicon layers. ${ }^{113}$ We have investigated several reagents for Ge deposition from $\mathrm{scCO}_{2}-\mathrm{CH}_{3} \mathrm{CN}$ and $\mathrm{scCH}_{2} \mathrm{~F}_{2} \cdot{ }^{6}$ For $\mathrm{Ge}$ (II) reagents the most promising results were obtained using $\left[\mathrm{N}^{n} \mathrm{Bu}_{4}\right]\left[\mathrm{GeCl}_{3}\right]$. Better results were obtained using $\mathrm{GeCl}_{4}$. Fig. 20 shows the phase behaviour for binary mixtures of $\mathrm{CH}_{2} \mathrm{~F}_{2}$ with $\mathrm{GeCl}_{4}$ and $\left[\mathrm{N}^{n} \mathrm{Bu}_{4}\right] \mathrm{Cl}$. At $357 \mathrm{~K}$ and $15 \mathrm{MPa}$ the system forms a single phase, supercritical system. Fig. 21 shows typical cyclic voltammograms of $\mathrm{GeCl}_{4}$ in $\mathrm{scCH}_{2} \mathrm{~F}_{2}$ under these conditions. At the $250 \mu \mathrm{m} \mathrm{Au}$ disc electrode reduction starts at $\sim 0.7 \mathrm{~V} v s$. Pt followed by a less well resolved increase in current cathodic of $-1.5 \mathrm{~V}$, presumably corresponding to the two-step reduction of $\mathrm{GeCl}_{4}$. In the limiting current region there are large, random fluctuations in the reduction current. These fluctuations arise from unsteady convective flow in the highpressure electrochemistry cell because of the low viscosity of the fluid when the operating conditions are close to the critical 


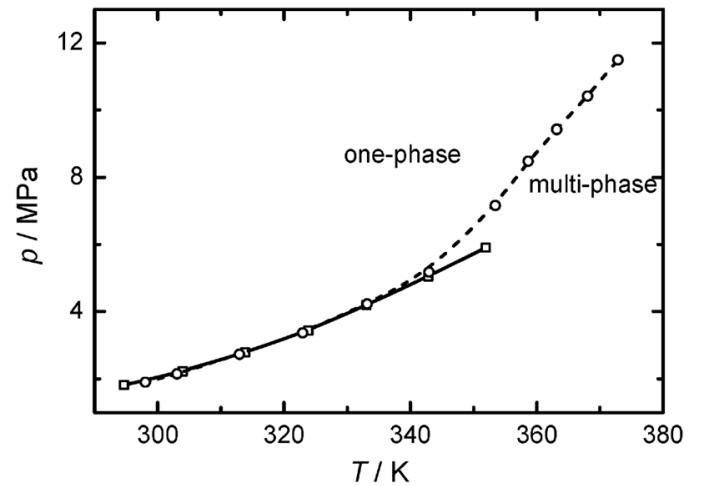

Fig. $20 p-T$ phase diagrams of the binary mixtures of $\mathrm{CH}_{2} \mathrm{~F}_{2}+\mathrm{A}: \mathrm{A}=$ $\mathrm{GeCl}_{4}(\square), x_{\mathrm{A}}=4.4 \times 10^{-3}$; and $\mathrm{A}=\left[\mathrm{N}^{n} \mathrm{Bu}_{4}\right] \mathrm{Cl}(O), x_{\mathrm{A}}=2.95 \times 10^{-3.6}$.

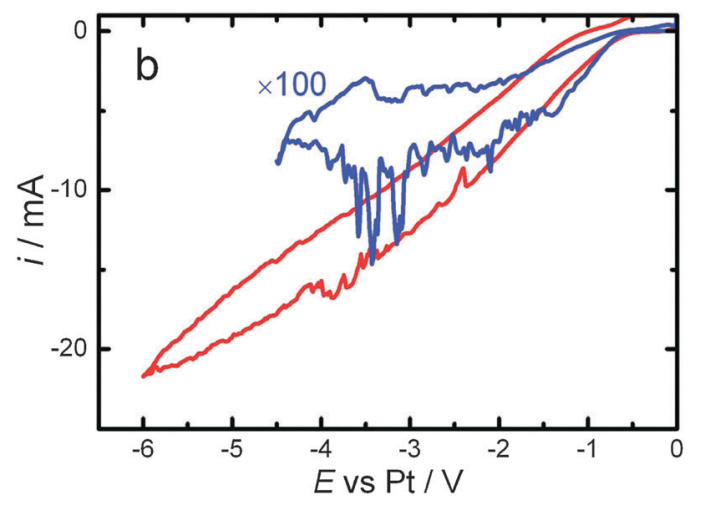

Fig. 21 Cyclic voltammogram of $0.06 \mathrm{~mol} \mathrm{dm}^{-3} \mathrm{GeCl}_{4}$ in $\mathrm{scCH}_{2} \mathrm{~F}_{2}$ with $0.06 \mathrm{~mol} \mathrm{dm}^{-3}\left[\mathrm{~N}^{n} \mathrm{Bu}_{4}\right] \mathrm{Cl}$ as the supporting electrolyte. The working electrodes were a $250 \mu \mathrm{m}$ Au microdisc (blue line, scan rate $0.1 \mathrm{~V} \mathrm{~s}^{-1}$ ), and a $0.36 \mathrm{~cm}^{2}$ gold-coated glass slide (red line, scan rate $0.1 \mathrm{~V} \mathrm{~s}^{-1}$ ). The measurements were carried out at $357 \mathrm{~K}$ and $15 \mathrm{MPa}{ }^{6}$

point of $\mathrm{CH}_{2} \mathrm{~F}_{2}$. We can also see that there is significant $i R$ drop in this case. This is because the conductivity of the $\left[\mathrm{N}^{n} \mathrm{Bu} 4\right] \mathrm{Cl}$ supporting electrolyte is low in $\mathrm{scCH}_{2} \mathrm{~F}_{2}$. These conditions can be used for bulk deposition of $\mathrm{Ge}$, the 'as deposited' material was amorphous, but crystallised under high intensity laser illumination. ${ }^{6}$

\section{Templates}

Electrodeposition into small and high aspect ratio pore structures is a specific advantage of SCFED, and provides opportunities to grow high aspect ratio nanowires or to construct multi-component devices in electrically directed locations. Aligned pore structures will need to be used in future to deliver the promise of linking properties to designed nanostructures.

Electrochemical reaction of aluminium in an acidic environment is well known to produce porous anodic aluminium oxide (AAO) films and well-ordered hexagonal AAO films (Fig. 22a) are achievable if the anodisation conditions are well optimised. ${ }^{114-116}$ These materials can be produced with pore sizes from around $5 \mathrm{~nm}^{117}$ to $500 \mathrm{~nm},{ }^{118}$ and the resulting templates are electrically and thermally insulating, optically transparent and robust. Typically they are grown on the surface of a solid aluminium foil electrodes, but can also be produced in sputtered aluminium films on other surfaces such as ITO-glass, ${ }^{119}$ suggesting opportunities to make porous structures on various substrates. Several authors have published electrodeposition of metals and other materials into these structures from more conventional electrolytes. ${ }^{120,121}$ Many of these porous films are now commercially produced, where they are cleaved from the aluminium surface to produce self-supporting membranes. The chemistry to produce similar structures in other oxides, especially titanium dioxide, is also now well developed. ${ }^{122}$

Surfactant- and block copolymer-templated porous films are the commonest porous materials with small pore sizes, with pores ranging from below $3 \mathrm{~nm}$ to above $10 \mathrm{~nm}$. It is possible to produce a variety of 1-, 2- or 3-dimensional pore structures controlled by a combination of surfactant type, concentration and temperature. Evaporation induced self-assembly (EISA) is a process in which the concentration increase that results from solvent evaporation during coating drives both the formation of micelles from the surfactant and condensation of the silica species in the sol. However, the EISA process is difficult to control. The linear pores that are present in hexagonal phase silica are particularly attractive hosts for electrodeposition and are the most heavily studied morphology. The alignment of the pores is controlled by the relative strength of the interaction between the micelle surfaces and the substrate compared with micelle-micelle interactions. In most cases the pores are either randomly oriented (referred to as "worm-like") or are parallel to the substrate. ${ }^{128}$ Parallel pores can be brought into long range alignment (Fig. 22b) by the addition of a low molar mass homopolymer to a block copolymer template film and then infiltrating a tetraethylorthosilicate (TEOS) precursor as a supercritical $\mathrm{CO}_{2}$ solution. ${ }^{123}$ Filling pores in this orientation is very interesting from an applications viewpoint due to the anisotropy that is present in the plane of the film, but pore access is more limited than in films with pores perpendicular to the film surface.

The tendency for pores to align with the substrate surface has been used to good effect in formation of mesoporous silica inside AAO membranes. ${ }^{129}$ These have well-formed larger pores that are perpendicular to the face of the membrane. When a silica sol containing a surfactant at an appropriate concentration is infiltrated into one of these membranes the mesopores can be oriented along the length of the host pore (columnar growth) or can form toroidal or helical channels depending on deposition conditions. High humidity is frequently the key parameter in obtaining columnar growth, which is the most accessible morphology for electrodeposition (although electrodeposition into the other structure types has also been demonstrated). Copper, silver and tellurium nanowires have already been deposited in larger (P123-templated) columnar pores synthesised in this way (Fig. 22c). ${ }^{124}$

Thin hexagonal mesoporous films with pores perpendicular to the plane of the film have been grown at an oil-water interface using CTAB (cetyltrimethylammonium bromide) surfactant. ${ }^{130}$ These films were very thin and not useful as electrodeposition hosts. However, Nagarajan et al. have shown that supercritical 

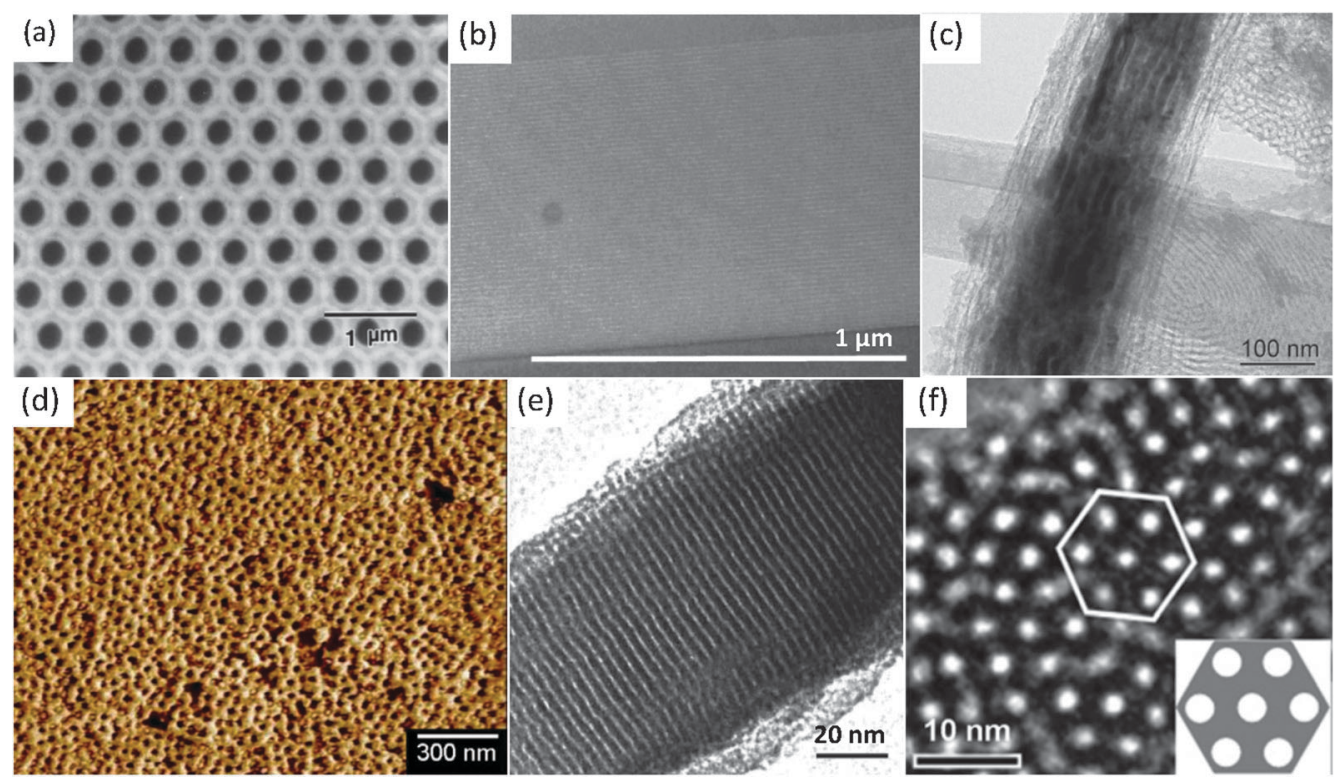

Fig. 22 Images of ordered porous structures. (a) SEM of anodically oxidised alumina with a hexagonal array of large ordered pores ${ }^{118}$ (Copyright 1998 The Japan Society of Applied Physics). (b) Cross-sectional TEM of long range ordered pores parallel to substrate surface produced from a block copolymer-homopolymer blend ${ }^{123}(1 \mu \mathrm{m}$ scale bar; reprinted (adapted) with permission from V. R. Tirumala et al., Chem. Mater., $2007,19,5868$. Copyright 2007, American Chemical Society). (c) Cu nanowires in columnar mesoporous silica originally grown in AAO ${ }^{124}$ (reprinted (adapted) with permission from A. Keilbach et al., Chem. Mater., 2010, 22, 5430. Copyright 2007, American Chemical Society). (d) Phase scanning force micrograph of a block copolymer film with cylindrical domains perpendicular to the surface infused with silica ${ }^{125}$ (C) WILEY-VCH Verlag GmbH \& Co. KGaA, Weinheim). (e) A cross-sectional TEM of an EASA-derived film with well-aligned perpendicular pores ${ }^{126}$ (reprinted by permission from Macmillan Publishers Ltd.: A. Walcarius et al., Nat. Mater., 6, 602, copyright 2007). (f) TEM of a flake of Stöber silica film showing the hexagonal pore structure ${ }^{127}$ (20 nm scale bar; (C) 2012 Wiley-VCH Verlag GmbH \& Co. KGaA, Weinheim).

$\mathrm{CO}_{2}$ infiltration of TEOS into spin-coated films of the amphiphilic block copolymer, poly( $\alpha$-methyl styrene- $\beta$-hydroxy styrene), which exhibits orientation of the cylindrical microdomains perpendicular to the film surface, results in perpendicular pore structures with pore sizes of $20 \mathrm{~nm}$ or larger (Fig. 22d). ${ }^{125}$ These could be grown on conductive surfaces and hence be useful electrodeposition hosts. Recently three approaches have used more conventional surfactant-silica sol mixtures to make well-ordered hexagonal pore structures. Tolbert used a (111)-oriented cubic porous titania film as the substrate for growth of hexagonal porous silica, with the surfactant chosen to give a lattice match such that the perpendicular pore structure is inherently favoured from the base of the pores. ${ }^{131}$ Walcarius has used an "Electro-assisted self-assembly" (EASA) method to control pore orientation. ${ }^{126,132}$ The application of an electric field has two roles in this method, it aids the formation of micelles from the cationic surfactant (CTAB) on the electrode at the same time as generating hydroxyl ions via water oxidation which aids local condensation of the sol particles at the electrode surface. This method produces well-aligned pores with $\sim 3 \mathrm{~nm}$ diameter (Fig. 22e) in films with thickness up to $\sim 100 \mathrm{~nm}$. A key advantage is that a conductive substrate, typically indium tin oxide (ITO), is used in growth and so is inherently available as the electrode for electrodeposition. Thicker films with similar pore size can be grown by a related route developed by Zhao and carried out with a dilute Stöber silica solution containing CTAB. ${ }^{127}$ The method relies on the formation of CTAB micelles at the substrate surface under weakly basic conditions in which TEOS undergoes slow hydrolysis and again produces a hexagonal array of pores perpendicular to the substrate surface (Fig. 22f). Whilst these films do not need to be grown on conductive surfaces the authors report the best ordered films on ITO.

Fig. 23 shows results for the deposition of copper into nanoscale $(<10 \mathrm{~nm})$ pores. The templates were prepared by

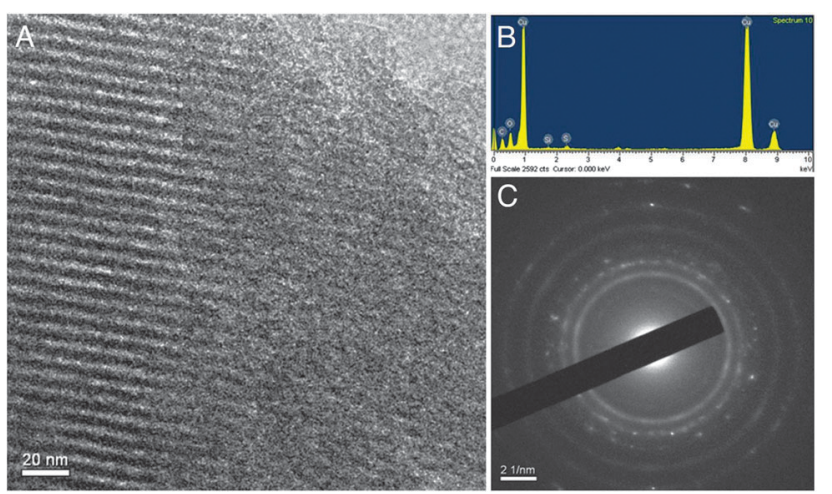

Fig. 23 Copper nanorods in mesoporous silica. (A) TEM of copper nanorods electrodeposited into silica mesopores from a solution of $\mathrm{scCO}_{2}$ with 12.1 wt\% $\mathrm{CH}_{3} \mathrm{CN}, 20 \mathrm{mM}\left[\mathrm{N}^{n} \mathrm{Bu}_{4}\right]\left[\mathrm{B}\left\{3,5-\mathrm{C}_{6} \mathrm{H}_{3}\left(\mathrm{CF}_{3}\right)_{2}\right\}_{4}\right]$, and $2 \mathrm{mM}$ $\left[\mathrm{Cu}\left(\mathrm{CH}_{3} \mathrm{CN}\right)_{4}\right]\left[\mathrm{B}\left\{3,5-\mathrm{C}_{6} \mathrm{H}_{3}\left(\mathrm{CF}_{3}\right)_{2}\right\}_{4}\right]$ at $311 \mathrm{~K}$ and $17.24 \mathrm{MPa}$. The working electrode was a $0.8 \times 0.5 \mathrm{~cm}$ ITO on glass slide modified with approximately $250 \mathrm{~nm}$ thick film of mesoporous silica; the counter electrode was a large, coiled, copper wire and the reference electrode was a $0.5 \mathrm{~mm}$ diameter copper disc. (B) EDX spectrum recorded from the same TEM sample. (C) Selected area electron diffraction (SAED) pattern recorded on 1 of the copper rods. ${ }^{5}$ 
dip coating ITO slides in a solution of Brij56, TMOS, $0.5 \mathrm{M} \mathrm{HCl}$ and $\mathrm{MeOH}(1: 1.8: 1: 3.8$ by weight). After calcining, this produces an adherent mesoporous silica film roughly $200 \mathrm{~nm}$ thick containing a regular hexagonal array of approximately $3 \mathrm{~nm}$ diameter cylindrical pores approximately $6 \mathrm{~nm}$ apart but randomly aligned with respect to the substrate. Electrochemical deposition of copper was carried out from $\left[\mathrm{Cu}\left(\mathrm{CH}_{3} \mathrm{CN}\right)_{4}\right]\left[\mathrm{B}\left\{3,5-\mathrm{C}_{6} \mathrm{H}_{3}\left(\mathrm{CF}_{3}\right)_{2}\right\}_{4}\right]$ in $\mathrm{scCO}_{2}-$ $\mathrm{CH}_{3} \mathrm{CN}$ containing $20 \mathrm{mM}\left[\mathrm{N}^{n} \mathrm{Bu}_{4}\right]\left[\mathrm{B}\left\{3,5-\mathrm{C}_{6} \mathrm{H}_{3}\left(\mathrm{CF}_{3}\right)_{2}\right\}_{4}\right]$. The TEM image in Fig. 23A shows the regular array of cylindrical pores clearly visible in cross section on the left hand side of the image. Evidence that the pores are filled with copper is provided by the EDX analysis, which shows strong copper as well as the expected silicon and oxygen signals, Fig. 23B, and by the selected area electron diffraction results, Fig. 23C, which show a combination of diffuse rings attributed to silica together with rings that are consistent with the expected (111), (200), (220), and (311) diffraction peaks for copper. These results demonstrate the proof-of-principle, but much remains to be done to improve alignment and produce nanowire devices.

\section{Conclusions and future prospects}

The barriers to successful electrodeposition from a supercritical fluid are significant, but the field has now progressed beyond the stage of preliminary studies to the point where generally applicable methods for supercritical fluid electrodeposition have been developed. An important contribution has been to establish a range of supporting electrolytes capable of achieving high ionic conductivities in the low dielectric constant fluids. Supercritical fluid electrodeposition has been used to deposit a range of different materials, e.g. $\mathrm{Ag}, \mathrm{Cu}$, and Ge, from complex ions with different overall charges, different ligand types and with different oxidation states. It has been demonstrated that a range of supercritical fluids, including both those with moderate dielectric constants and those with low dielectric constant when combined with a suitable cosolvent, can be used to electrodeposit films. Whilst not every combination of supercritical fluid and target material will be possible, the existing work clearly indicates that the range of materials that can be deposited could be expanded significantly, for example to a wider range of metals, semiconductors, binary and ternary compounds and alloys. The work so far has demonstrated that, by suitable design and choice of the combination of anion and cation, it is possible to achieve supercritical fluid electrolytes with surprisingly large conductivities that will allow deposition at sufficiently high rates to be useful. The field of supercritical fluid electrodeposition is still at an early stage but progress has been good and the prospects are very encouraging. In taking this work forward our increasing knowledge of the underpinning physical chemistry, in terms of the phase behaviour of the supercritical fluid mixtures, the solubility, stability and conductivity of electrolytes and complex reagents in supercritical fluids, the phase behaviour of supercritical fluids in confined spaces, the structure of the double layer at the supercritical fluid/electrode interface, the kinetics of ligand exchange and electron transfer reactions in supercritical fluids, etc., will be very important.

Considerable advances have been achieved in the field of supercritical fluid electrodeposition, but it is important not to lose sight of the fact that electrodeposition from a supercritical fluid will always involve significant practical challenges due to the high pressures involved. This means that supercritical fluid electrodeposition will only become technologically important if there are very clear advantages and novel applications which only supercritical fluid electrodeposition can fulfil. The particular properties of supercritical fluids strongly suggest that just such novel applications will exist, most probably in the area of complex and extreme nanostructures. However, as yet definitive proof of this has not been demonstrated and this has to be one of the key priorities for the field. What are the most likely candidates for these novel applications? One way of viewing supercritical fluid electrodeposition is as an extension of nonaqueous electrodeposition to higher temperature. Whilst lower deposition temperatures are often advantageous economically, better material quality, e.g. crystallinity, often requires an elevated deposition temperature. For any specific solvent the critical temperature is a fundamental limit above which electrodeposition can only be performed using the supercritical fluid electrodeposition technique. One area in which supercritical fluids are already showing promise is their ability to penetrate into very small pores. In particular supercritical fluid electrochemistry has been used to electrodeposit into $3 \mathrm{~nm}$ pores within mesoporous silicas.

It will take some time, and more work, to discover whether supercritical fluid electrodeposition can open up novel areas in nanomaterials and structures; however there are a number of shorter term goals which will enable the field to develop into new and exciting areas. These include, from a physical chemistry perspective, a better understanding of the structure of the double layer and of electrolyte solvation in supercritical fluids, studies of electron transfer kinetics at the electrode supercritical fluid interface, studies of speciation in supercritical fluids, and a greater understanding of the phase behaviour of supercritical fluids and supercritical fluid electrolytes in confined spaces. In addition there is much scope for practical advances in the design of new cells, in solvent purification and for the application of supercritical fluids in electrosynthesis.

In conclusion, supercritical fluid electrochemistry has come a long way in a relatively short time and has achieved a number of goals which many people thought were not possible. It is an exciting field with significant scientific challenges and we hope that this perspective will stimulate others to consider how electrochemistry in supercritical fluids might be applied not only in materials deposition, but also in other areas.

\section{Acknowledgements}

This work is part of the Supercritical Fluid Electrodeposition project (www.scfed.net) which is a multidisciplinary collaboration of British universities investigating the fundamental and 
applied aspects of supercritical fluids funding by a Programme Grant from the EPSRC (EP/I013394/1). MWG gratefully acknowledges receipt of a Wolfson Merit award. We thank $\mathrm{K}$. Thaller for help in preparation of the manuscript.

\section{References}

1 J. M. Blackburn, D. P. Long, A. Cabanas and J. J. Watkins, Science, 2001, 294, 141-145.

2 V. K. Popov, V. N. Bagratashvili, L. I. Krotova, A. O. Rybaltovskii, D. C. Smith, P. S. Timashev, J. Yang, Y. S. Zavorotnii and S. M. Howdle, Green Chem., 2011, 13, 2696-2700.

3 M. Schlesinger and M. Paunovic, Modern Electroplating, Wiley, New York, 5th edn, 2010.

4 M. Paunovic and M. Schlesinger, Fundamentals of Electrochemical Deposition, Wiley, New York, 2006.

5 J. Ke, W. T. Su, S. M. Howdle, M. W. George, D. Cook, M. Perdjon-Abel, P. N. Bartlett, W. Zhang, F. Cheng, W. Levason, G. Reid, J. Hyde, J. Wilson, D. C. Smith, K. Mallik and P. Sazio, Proc. Natl. Acad. Sci. U. S. A., 2009, 106, 14768-14772.

6 J. Ke, P. N. Bartlett, D. Cook, T. L. Easun, M. W. George, W. Levason, G. Reid, D. Smith, W. Su and W. Zhang, Phys. Chem. Chem. Phys., 2012, 14, 1517-1528.

7 W. Lu and C. M. Lieber, Nat. Mater., 2007, 6, 841-850.

8 R. Skomski, J. Phys.: Condens. Matter, 2003, 15, R841-R896.

9 J. Wang, Biosens. Bioelectron., 2006, 21, 1887-1892.

10 C. J. Vineis, A. Shakouri, A. Majumdar and M. G. Kanatzidis, Adv. Mater., 2010, 22, 3970-3980.

11 B. Tian, T. J. Kempa and C. M. Lieber, Chem. Soc. Rev., 2009, 38, 16-24.

12 Z. L. Wang, Mater. Today, 2007, 10, 20-28.

13 T. Zhu and J. Li, Prog. Mater. Sci., 2010, 55, 710-757.

14 L. Cademartiri and G. A. Ozin, Adv. Mater., 2009, 21, 1013-1020.

15 R. D. Smith, B. W. Wright and C. R. Yonker, Anal. Chem., 1988, 60, 1323A.

16 M. Poliakoff, S. M. Howdle and S. G. Kazarian, Angew. Chem., Int. Ed. Engl., 1995, 34, 1275-1295.

17 R. S. Oakes, A. A. Clifford and C. M. Rayner, J. Chem. Soc., Perkin Trans. 1, 2001, 917-941.

18 D. J. Cole-Hamilton, Adv. Synth. Catal., 2006, 348, 1341-1351.

19 P. Licence and M. Poliakoff, NATO Sci. Ser., II, 2008, 246, 171-191.

20 K. P. Johnston and R. P. da Rocha Sandro, J. Supercrit. Fluids, 2009, 47, 523-530.

21 J. Yang, T. Hasell, D. C. Smith and S. M. Howdle, J. Mater. Chem., 2009, 19, 8560-8570.

22 M. Perrut, Ind. Eng. Chem. Res., 2000, 39, 4531-4535.

23 M. Herrero, A. Cifuentes and E. Ibanez, Food Chem., 2006, 98, 136-148.

24 J. J. A. Barry, M. M. C. G. Silva, V. K. Popov, K. M. Shakesheff and S. M. Howdle, Philos. Trans. R. Soc. London, Ser. A, 2006, 364, 249-261.
25 M. Banchero, S. Sicardi, A. Ferri and L. Manna, Text. Res. J., 2008, 78, 217-223.

26 J. O'Regan, S. Preston and A. Dunne, 13th European Biosolids \& Organic Resources Conference and Workshop, 2008.

27 C. J. Tighe, R. Q. Cabrera, R. I. Gruar and J. A. Darr, Ind. Eng. Chem. Res., 2013, 52, 5522-5528.

28 M. A. McHugh and V. J. Krukonis, Supercritical Fluid Extraction: Principles and Practice, Butterworth, Oxford, 1986.

29 J. F. Brennecke and C. A. Eckert, AIChE J., 1989, 35, 1409-1427.

30 E. Kiran and J. F. Brennecke, Supercritical Fluid Engineering Science: Fundamentals and Applications, ACS Symp. Ser. 514, ACS, 1993.

31 A. A. Clifford, Chromatogr.: Princ. Pract., 1999, 2, 1-14.

32 N. R. Foster, F. P. Lucien and R. Mammucari, Handbook of Green Chemistry, Wiley-VCH, 2010, vol. 4, pp. 77-100.

33 M. Skerget, Z. Knez and M. Knez-Hrncic, J. Chem. Eng. Data, 2011, 56, 694-719.

34 P. N. Bartlett, D. C. Cook, M. W. George, J. Ke, W. Levason, G. Reid, W. Su and W. Zhang, Phys. Chem. Chem. Phys., 2010, 12, 492-501.

35 P. Ratanajiajaroen and M. Ohshima, J. Supercrit. Fluids, 2012, 68, 31-38.

36 Y. Liang, C. Zhen, D. Zou and D. Xu, J. Am. Chem. Soc., 2004, 126, 16338-16339.

37 K. Izutsu, Electrochemistry in nonaqueous solutions, John Wiley \& Sons, 2009.

38 A. P. Abbott, C. A. Eardley and R. Tooth, J. Chem. Eng. Data, 1999, 44, 112-115.

39 D. Bertolini, M. Cassettari and G. Salvetti, J. Mol. Liq., 1984, 28, 175-189.

40 K. Reuter, S. Rosenzweig and E. U. Franck, Physica A, 1989, 156, 294-302.

41 F. G. Keyes and J. G. Kirkwood, Phys. Rev., 1930, 36, 754-761.

42 G. Ritzoulis, N. Papadopoulos and D. Jannakoudakis, J. Chem. Eng. Data, 1986, 31, 146-148.

43 A. P. Abbott, E. G. Hope, R. Mistry and A. M. Stuart, Green Chem., 2009, 11, 1530-1535.

44 T. S. Reighard, S. T. Lee and S. V. Olesik, Fluid Phase Equilib., 1996, 123, 215-230.

45 A. K. Dillow, J. S. Brown, C. L. Liotta and C. A. Eckert, J. Phys. Chem. A, 1998, 102, 7609-7617.

46 H.-K. Bae, J.-H. Jeon and H. Lee, Fluid Phase Equilib., 2004, 222-223, 119-125.

47 M. Caravati, J.-D. Grunwaldt and A. Baiker, Appl. Catal., A, 2006, 298, 50-56.

48 J. R. Forero-Mendieta, H. I. Castro-Vargas, F. ParadaAlfonso and J. A. Guerrero-Dallos, J. Supercrit. Fluids, 2012, 68, 64-70.

49 J. Liu, E. L. Regalado, I. Mergelsberg and C. J. Welch, Org. Biomol. Chem., 2013, 11, 4925-4929.

50 D. Cook, P. N. Bartlett, W. Zhang, W. Levason, G. Reid, J. Ke, W. Su, M. W. George, J. Wilson, D. Smith, K. Mallik, E. Barrett and P. Sazio, Phys. Chem. Chem. Phys., 2010, 12, 11744-11752. 
51 P. Licence, M. P. Dellar, R. G. M. Wilson, P. A. Fields, D. Litchfield, H. M. Woods, M. Poliakoff and S. M. Howdle, Rev. Sci. Instrum., 2004, 75, 3233-3236.

52 P. N. Bartlett, D. C. Cook, M. W. George, J. Ke, W. Levason, G. Reid, W. Su and W. Zhang, Phys. Chem. Chem. Phys., 2011, 13, 190-198.

53 J. A. Darr and M. Poliakoff, Chem. Rev., 1999, 99, 495-541.

54 R. A. Williams and S. Naiditch, Phys. Chem. Liq., 1970, 2, 67-75.

55 G. Silvestri, S. Gambino, G. Filardo, C. Cuccia and E. Guarino, Angew. Chem., Int. Ed. Engl., 1981, 20, 101-102.

56 R. M. Crooks and A. J. Bard, J. Phys. Chem., 1987, 91, 1274-1284.

57 R. M. Crooks and A. J. Bard, J. Electroanal. Chem., 1988, 240, 253-279.

58 R. M. Crooks, F. R. F. Fan and A. J. Bard, J. Am. Chem. Soc., 1984, 106, 6851-6852.

59 W. M. Flarsheim, A. J. Bard and K. P. Johnston, J. Phys. Chem., 1989, 93, 4234-4242.

60 W. M. Flarsheim, Y. M. Tsou, I. Trachtenberg, K. P. Johnston and A. J. Bard, J. Phys. Chem., 1986, 90, 3857-3862.

61 C. Y. Liu, S. R. Snyder and A. J. Bard, J. Phys. Chem. B, 1997, 101, 1180-1185.

62 A. C. McDonald, F. R. F. Fan and A. J. Bard, J. Phys. Chem., 1986, 90, 196-202.

63 C. R. Cabrera and A. J. Bard, J. Electroanal. Chem., 1989, 273, 147-160.

64 R. M. Crooks and A. J. Bard, J. Electroanal. Chem., 1988, 243, 117-131.

65 C. R. Cabrera, E. Garcia and A. J. Bard, J. Electroanal. Chem., 1989, 260, 457-460.

66 A. P. Abbott and J. C. Harper, J. Chem. Soc., Faraday Trans., 1996, 92, 3895-3898.

67 S. F. Dressman and A. C. Michael, Anal. Chem., 1995, 67, 1339-1345.

68 V. A. Grinberg and V. M. Mazin, Russ. J. Electrochem., 1998, 34, 223-229.

69 S. A. Olsen and D. E. Tallman, Anal. Chem., 1994, 66, 503-509.

70 D. L. Goldfarb and H. R. Corti, Electrochem. Commun., 2000, 2, 663-670.

71 D. L. Goldfarb and H. R. Corti, J. Phys. Chem. B, 2004, 108, 3358-3367.

72 D. L. Goldfarb and H. R. Corti, J. Phys. Chem. B, 2004, 108, 3368-3375.

73 A. P. Abbott, C. A. Eardley, J. C. Harper and E. G. Hope, J. Electroanal. Chem., 1998, 47, 1-4.

74 A. P. Abbott and C. A. Eardley, J. Phys. Chem. B, 2000, 104, 775-779.

75 A. P. Abbott, E. G. Hope and D. J. Palmer, Anal. Chem., 2005, 77, 6702-6708.

76 A. P. Abbott and N. E. Durling, Phys. Chem. Chem. Phys., 2001, 3, 579-582.

77 A. P. Abbott and C. A. Eardley, J. Phys. Chem. B, 1999, 103, 6157-6159.
78 A. P. Abbott and J. C. Harper, Phys. Chem. Chem. Phys, 1999, 1, 839-841.

79 S. A. Olsen and D. E. Tallman, Anal. Chem., 1996, 68, 2054-2061.

80 R. M. Fuoss and C. A. Kraus, J. Am. Chem. Soc., 1933, 55, 2387-2399.

81 A. P. Abbott and C. A. Eardley, J. Phys. Chem. B, 2000, 104, 9351-9355.

82 J. Jun and P. S. Fedkiw, J. Electroanal. Chem., 2001, 515, 113-122.

83 S. H. Strauss, Chem. Rev., 1993, 93, 927-942.

84 I. Krossing and I. Raabe, Angew. Chem., Int. Ed., 2004, 43, 2066-2090.

85 C. E. Moore, F. P. Cassaretto, H. Posvic and J. J. McLafferty, Anal. Chim. Acta, 1966, 35, 1-5.

86 J. T. Vandeberg, C. E. Moore, F. P. Cassareto and H. Posvic, Anal. Chim. Acta, 1969, 44, 175-183.

87 M. Brookhart, B. Grant and A. F. Volpe Jr., Organometallics, 1992, 11, 3920-3922.

88 P. N. Bartlett, D. C. Cook, M. W. George, J. Ke, W. Levason, G. Reid, W. T. Su and W. J. Zhang, Phys. Chem. Chem. Phys., 2010, 12, 492-501.

89 A. P. Abbott and D. J. Schiffrin, J. Chem. Soc., Faraday Trans., 1990, 86, 1453-1459.

90 H. O. House, E. Feng and N. P. Peet, J. Org. Chem., 1971, 36, 2361-2371.

91 D. Cook, P. N. Bartlett, W. Zhang, W. Levason, G. Reid, J. Ke, W. T. Su, M. W. George, J. Wilson, D. Smith, K. Mallik, E. Barrett and P. Sazio, Phys. Chem. Chem. Phys, 2010, 12, 11744-11752.

92 B. J. Hathaway and A. E. Underhill, J. Chem. Soc., 1960, 3705-3711.

93 B. J. Hathaway and A. E. Underhill, J. Chem. Soc., 1962, 2444-2449.

94 J. Kubas, Inorg. Synth., 1979, 19, 90.

95 P. N. Bartlett, M. Perdjon-Abel, D. Cook, G. Reid, W. Levason, F. Cheng, W. Zhang, M. W. George, J. Ke, R. Beanland and J. Sloan, ChemElectroChem, 2014, 1, 187-194.

96 W. Levason, G. Reid and W. Zhang, Coord. Chem. Rev., 2011, 255, 1319-1341.

97 F. Cheng, M. F. Davis, A. L. Hector, W. Levason, G. Reid, M. Webster and W. Zhang, Eur. J. Inorg. Chem., 2007, 4897-4905.

98 P. E. Anderson, R. N. Badlani, J. Mayer and P. A. Mabrouk, J. Am. Chem. Soc., 2002, 124, 10284-10285.

99 H. Yan, T. Sato, D. Komago, A. Yamaguchi, K. Oyaizu, M. Yuasa and K. Otake, Langmuir, 2005, 21, 12303-12308.

100 M. Atobe, H. Ohsuka and T. Fuchigami, Chem. Lett., 2004, 618-619.

101 H. Yoshida, M. Sone, A. Mizushima, K. Abe, X. T. Tao, S. Ichihara and S. Miyata, Chem. Lett., 2002, 1086-1087.

102 H. Yoshida, M. Sone, A. Mizushima, H. Yan, H. Wakabayashi, K. Abe, X. T. Tao, S. Ichihara and S. Miyata, Surf. Coat. Technol., 2003, 173, 285-292. 
103 H. Yan, M. Sone, A. Mizushima, T. Nagai, K. Abe, S. Ichihara and S. Miyata, Surf. Coat. Technol., 2004, 187, 86-92.

104 T.-F. M. Chang and M. Sone, Surf. Coat. Technol., 2011, 205, 3890-3899.

105 M. Jikei, S. Saitoh, H. Yasuda, H. Itoh, M. Sone, M.-A. Kakimoto and H. Yoshida, Polymer, 2006, 47, 1547-1554.

106 N. Shinoda, T. Shimizu, T.-F. M. Chang, A. Shibata and M. Sone, Thin Solid Films, 2013, 529, 29-33.

107 D. E. Niehaus, M. Philips, A. Michael and R. M. Wightman, J. Phys. Chem., 1989, 93, 6232-6236.

108 K. D. Tilly, N. R. Foster, S. J. Macnaughton and D. L. Tomasko, Ind. Eng. Chem. Res., 1994, 33, 681-688.

109 Y. Houndonougbo, B. B. Laird and K. Kuczera, J. Chem. Phys., 2007, 126, 074507.

110 V. A. Vas'ko, I. Tabakovic, S. C. Riemer and M. T. Kief, Microelectron. Eng., 2004, 75, 71-77.

111 A. Cabanas, X. Shan and J. J. Watkins, Chem. Mater., 2003, 15, 2910-2916.

112 M. L. Lee, E. A. Fitzgerald, M. T. Bulsara, M. T. Currie and A. Lochtefeld, J. Appl. Phys., 2005, 97, 011101.

113 R. Al-Salman, S. Z. El Abedin and F. Endres, Phys. Chem. Chem. Phys., 2008, 10, 4650-4657.

114 F. Keller, M. S. Hunter and D. L. Robinson, J. Electrochem. Soc., 1953, 100, 411-419.

115 H. Masuda and K. Fukuda, Science, 1995, 286, 1466-1468.

116 K. S. Napolskii, I. V. Roslyakov, A. Y. Romanchuk, K. O. O. A. S. Mankevich, V. A. Lebedev and A. A. Eliseev, J. Mater. Chem., 2012, 22, 11922-11926.

117 H. de Lira and R. Paterson, J. Membr. Sci., 2002, 206, 375-387.

118 H. Masuda, K. Yada and A. Osaka, Jpn. J. Appl. Phys., 1998, 37, L1340-L1342.
119 S. Z. Chuz, K. Wada, S. Inoue and S. Todoroki, J. Electrochem. Soc., 2002, 1149, B321-B327.

120 A. N. Belov, S. A. Gavrilov, V. I. Shevyakov and E. N. Redichev, Appl. Phys. A: Mater. Sci. Process., 2011, 102, 219-223.

121 M. S. Sander, A. L. Prieto, R. Gronsky, T. Sands and A. M. Stacy, Adv. Mater., 2002, 14, 665-667.

122 A. Ghicov and P. Schmuki, Chem. Commun., 2009, 2791-2808.

123 V. R. Tirumala, R. A. Pai, S. Agarwal, J. J. Testa, G. Bhatnagar, A. H. Romang, C. Chandler, B. P. Gorman, R. L. Jones, E. K. Lin and J. J. Watkins, Chem. Mater., 2007, 19, 5868-5874.

124 A. Keilbach, J. Moses, R. Köhn, M. Döblinger and T. Bein, Chem. Mater., 2010, 22, 5430-5436.

125 S. Nagarajan, M. Li, R. A. Pai, J. K. Bosworth, P. Busch, D.-M. Smilgies, C. K. Ober, T. P. Russell and J. J. Watkins, Adv. Mater., 2008, 20, 246-251.

126 A. Walcarius, E. Sibbottier, M. Etienne and J. Ghanbaja, Nat. Mater., 2007, 6, 602-608.

127 Z. Teng, G. Zheng, Y. Dou, W. Li, C.-Y. Mou, X. Zhang, A. M. Asiri and D. Zhao, Angew. Chem., Int. Ed., 2012, 51, 2173-2177.

128 V. V. Guliants, M. A. Carreon and Y. S. Lin, J. Membr. Sci., 2004, 235, 53-72.

129 P. Platschek, A. Keilbach and T. Bein, Adv. Mater., 2011, 23, 2395-2412.

130 S. Schacht, Q. Huo, I. G. Voight-Martin, G. D. Stucky and F. Schuth, Science, 1996, 273, 768-771.

131 E. K. Richman, T. Brezesinski and S. H. Tolbert, Nat. Mater., 2008, 7, 712-717.

132 A. Goux, M. Etienne, E. Aubert, C. Lecomte, J. Ghanbaja and A. Walcarius, Chem. Mater., 2009, 211, 731-741. 